\title{
Multi-scale comparative transcriptome analysis reveals key genes and metabolic reprogramming processes associated with oil palm fruit abscission
}

Kim Fooyontphanich ${ }^{1,2}$, Fabienne Morcillo ${ }^{1,3}$, Thierry Joët', Stéphane Dussert ${ }^{1}$, Julien Serret ${ }^{1}$, Myriam Collin ${ }^{1}$, Philippe Amblard ${ }^{4}$, Sithichoke Tangphatsornruang ${ }^{5}$, Peerapat Roongsattham ${ }^{1,6}$, Chatchawan Jantasuriyarat ${ }^{6}$, Jean-Luc Verdeil ${ }^{7,8}$ and Timothy J. Tranbarger ${ }^{*^{*}}$ (i)

\begin{abstract}
Background: Fruit abscission depends on cell separation that occurs within specialized cell layers that constitute an abscission zone (AZ). To determine the mechanisms of fleshy fruit abscission of the monocot oil palm (Elaeis guineensis Jacq.) compared with other abscission systems, we performed multi-scale comparative transcriptome analyses on fruit targeting the developing primary AZ and adjacent tissues.

Results: Combining between-tissue developmental comparisons with exogenous ethylene treatments, and naturally occurring abscission in the field, RNAseq analysis revealed a robust core set of 168 genes with differentially regulated expression, spatially associated with the ripe fruit $\mathrm{AZ}$, and temporally restricted to the abscission timing. The expression of a set of candidate genes was validated by qRT-PCR in the fruit AZ of a natural oil palm variant with blocked fruit abscission, which provides evidence for their functions during abscission. Our results substantiate the conservation of gene function between dicot dry fruit dehiscence and monocot fleshy fruit abscission. The study also revealed major metabolic transitions occur in the AZ during abscission, including key senescence marker genes and transcriptional regulators, in addition to genes involved in nutrient recycling and reallocation, alternative routes for energy supply and adaptation to oxidative stress.

Conclusions: The study provides the first reference transcriptome of a monocot fleshy fruit abscission zone and provides insight into the mechanisms underlying abscission by identifying key genes with functional roles and processes, including metabolic transitions, cell wall modifications, signalling, stress adaptations and transcriptional regulation, that occur during ripe fruit abscission of the monocot oil palm. The transcriptome data comprises an original reference and resource useful towards understanding the evolutionary basis of this fundamental plant process.
\end{abstract}

Keywords: Transcriptome, Fruit abscission, Abscission zone, Monocotyledon, Metabolic reprogramming, Elaeis guineensis

\footnotetext{
* Correspondence: timothy.tranbarger@ird.fr

'UMR DIADE, Institut de Recherche Pour le Développement, Université de

Montpellier, IRD Centre de Montpellier, 911 Avenue Agropolis BP 64501,

34394 Cedex 5 Montpellier, France

Full list of author information is available at the end of the article
}

\section{$\triangle B M C$}

(c) The Author(s). 2021 Open Access This article is licensed under a Creative Commons Attribution 4.0 International License, which permits use, sharing, adaptation, distribution and reproduction in any medium or format, as long as you give appropriate credit to the original author(s) and the source, provide a link to the Creative Commons licence, and indicate if changes were made. The images or other third party material in this article are included in the article's Creative Commons licence, unless indicated otherwise in a credit line to the material. If material is not included in the article's Creative Commons licence and your intended use is not permitted by statutory regulation or exceeds the permitted use, you will need to obtain permission directly from the copyright holder. To view a copy of this licence, visit http://creativecommons.org/licenses/by/4.0/. The Creative Commons Public Domain Dedication waiver (http://creativecommons.org/publicdomain/zero/1.0/) applies to the data made available in this article, unless otherwise stated in a credit line to the data. 


\section{Background}

Fruit abscission coordinates seed dispersal, which is essential for plant reproductive success. In an ecological setting, fruit that shed prematurely before seeds are fully developed, or too late during seasonal climate changes can jeopardize reproductive success of wild species. Fruit detachment mechanisms have also been a target of domestication, and a well-known domestication example is the non-abscising jointless mutant, which has been used to develop non-shedding tomato fruit cultivars [1]. This is also the case with cereals (rice, barley wheat, etc.) for which domestication has allowed the selection of varieties with non-shedding grains.

Indeed, fleshy fruit abscission is an important agronomic trait with widespread economic consequences [2]. Fruit bearing species with overly abundant immature fruit need to be thinned to obtain the optimal size and highest quality fruit. Crops with immature fruit that shed prematurely need to be inhibited to allow appropriate yields, while mature fruit that shed too soon need to be inhibited to facilitate harvest and avoid economic losses [3]. Whereas fruit abscission is conceptionally simple (i.e. the fruit separates from the plant and falls), the cell separation and regulatory mechanisms that allow fruit to be detached and shed involve highly spatially, temporally and environmentally regulated molecular and biochemical processes. Interactions between multiple signalling pathways that integrate the environment and the overall developmental and physiological status of the plant are necessary for fruit abscission to occur [4-9].

As with other plant organ abscission phenomenon, fruit abscission occurs through the function of a specialized tissue referred to as the abscission zone (AZ), located at the base of the organ to be shed, where breakdown of cell-to-cell adhesion occurs that results in cell separation and organ detachment [10]. The jointless tomato, which lacks a functional AZ, exemplifies the central role of the AZ for the abscission process [1]. Abscission zones can be classified into two general types based on their anatomy: 1) at the boundary region at the base of the organ to be shed and the neighbouring tissue, for example between a floral organ and the pedicel as observed in Arabidopsis or between the mesocarp and the pedicel as observed in oil palm fruit, and 2) within a tissue as observed in the pedicel of the tomato fruit or flower $[2,4]$. While the differentiation of these two AZ types may be different, in both cases once the AZ develops at the base of the organ to be shed, they must acquire competence to respond to signals required for cell separation and organ abscission $[4,6,11-14]$. After the AZ becomes competent for separation to be induced, cellular activity, in particular the expansion of the golgi vesicles and activation of the endomembrane system with the release of hydrolytic enzymes to the apoplast, leads to the degradation of the middle lamella and ultimately cell separation, and the organ is shed $[3,15,16]$.

Currently, the main model of monocot fleshy fruit abscission is from research on ripe fruit abscission of oil palm (Elaeis guineensis) of the palm family (Arecaceae). The oil palm fruit primary AZ is located at the junction between the mesocarp and the pedicel, and is a large multi-cell layer AZ, with minor adjacent AZs that separate later after separation in the primary $\mathrm{AZ}$ is complete $[17,18]$. Common to organ abscission in many species, ethylene or its precursor 1-aminocyclopropane-1-carboxylic acid (ACC) promotes, while auxin inhibits, cell separation in the primary AZ of the oil palm fruit $[19,20]$. Ethylene production is initiated in the apex of the ripe fruit mesocarp and progresses to the base of the mesocarp in a positive correlation to the percentage of separation that occurs in the primary AZ, which suggests ethylene may serve to link fruit ripening to fruit abscission [19]. The precise position of separation in the smaller adjacent AZs is determined by the age and ripeness of the fruit and depends upon completion of separation in the primary AZ [17]. In addition, while the vascular strands between the fruit base and the pedicel are continuous across the primary AZ, they are much less lignified and may facilitate organ removal [17].

The oil palm fruit primary AZ cells have high amounts of unmethylated pectin in the cell wall, in addition to increased polygalacturonase (PG) enzyme activity during abscission [21], which is also observed during fruit abscission of many species [22]. A further decrease in methylesterified homogalacturonan (HG), the most abundant pectin polymer, is detected particularly in AZ cells where cell separation occurs [23]. An oil palm fruit PG transcript (EgPG4) is abundant in the $\mathrm{AZ}$ in response to ethylene, and preferentially increased in the AZ cell layers prior to cell separation [20]. However, EgPG4 is also expressed in the mesocarp during ripening and is not specific to the AZ, and may function to dismantle the pectin rich cell walls in both tissues [20, 24]. Based on these results, while both demethylesterification and hydrolysis of the pectin HG appear to be important for cell separation in the AZ, it is unclear what other mechanisms are involved for cell separation to occur in the oil palm multi-cell-layer primary AZ.

In the present study, we undertake a large-scale multifaceted analysis of the transcriptional activity in the oil palm ripe fruit $\mathrm{AZ}$ induced by ethylene. We compared this expression with that of the neighbouring pedicel tissue treated with ethylene where no cell separation is observed, and with the expression in the AZ of unripe fruit that do not abscise when treated with ethylene. Expression was then validated in ripe fruit undergoing natural abscission under field conditions. Finally, we took advantage of a palm with an unusual non-abscission 
phenotype to validate the expression and function of selected candidate genes in the AZs of ripe fruit that do not undergo abscission [25]. Our approach allows an integrated view of the transcriptional activities, cellular processes and specificities that underlie the fruit abscission process in this monocot species.

\section{Results}

Identification of AZ-specific ethylene-responsive genes during ripe fruit abscission using multi-scale comparative transcriptome analysis

As a first step to screen for genes involved in oil palm ripe fruit abscission, we examined the short-term gene expression response in the fruit AZ at 150 Days after pollination (DAP) to an exogenous ethylene treatment. Transcriptome analysis was assessed every $3 \mathrm{~h}$ over a period of $12 \mathrm{~h}$, while cell separation was already observed after $9 \mathrm{~h}$ of treatment (Fig. 1a). We identified
1957 differentially expressed genes (DEGs) during at least one time point of the ethylene treatment in the 150 DAP sample (AZ150) compared to the control (time $0 \mathrm{~h}$ AZ150; Fig. 2a; Supplementary Table 1). Hierarchical clustering analysis identified 4 clusters of DEGs with different sub-clusters A1-A7, B1-B6, C1-C7, D1-D10 (Supplementary Fig. 1). Cluster A includes genes with a continuous increase of expression under ethylene treatment, while cluster $\mathrm{D}$ gathers genes down-regulated by ethylene. Genes belonging to clusters B and C display short-term responses to ethylene with maximal expression observed at 3 to $6 \mathrm{~h}$ respectively after initiation of exogenous ethylene application.

As a second step to screen the 1957 DEGs for AZ specific expression, we compared the short-term response of AZ150 to exogenous ethylene with those from the AZ from immature fruit at 30 DAP (AZ30; Fig. 1b-e) and the pedicel from ripe fruit (P150; Fig. 1a) samples (also

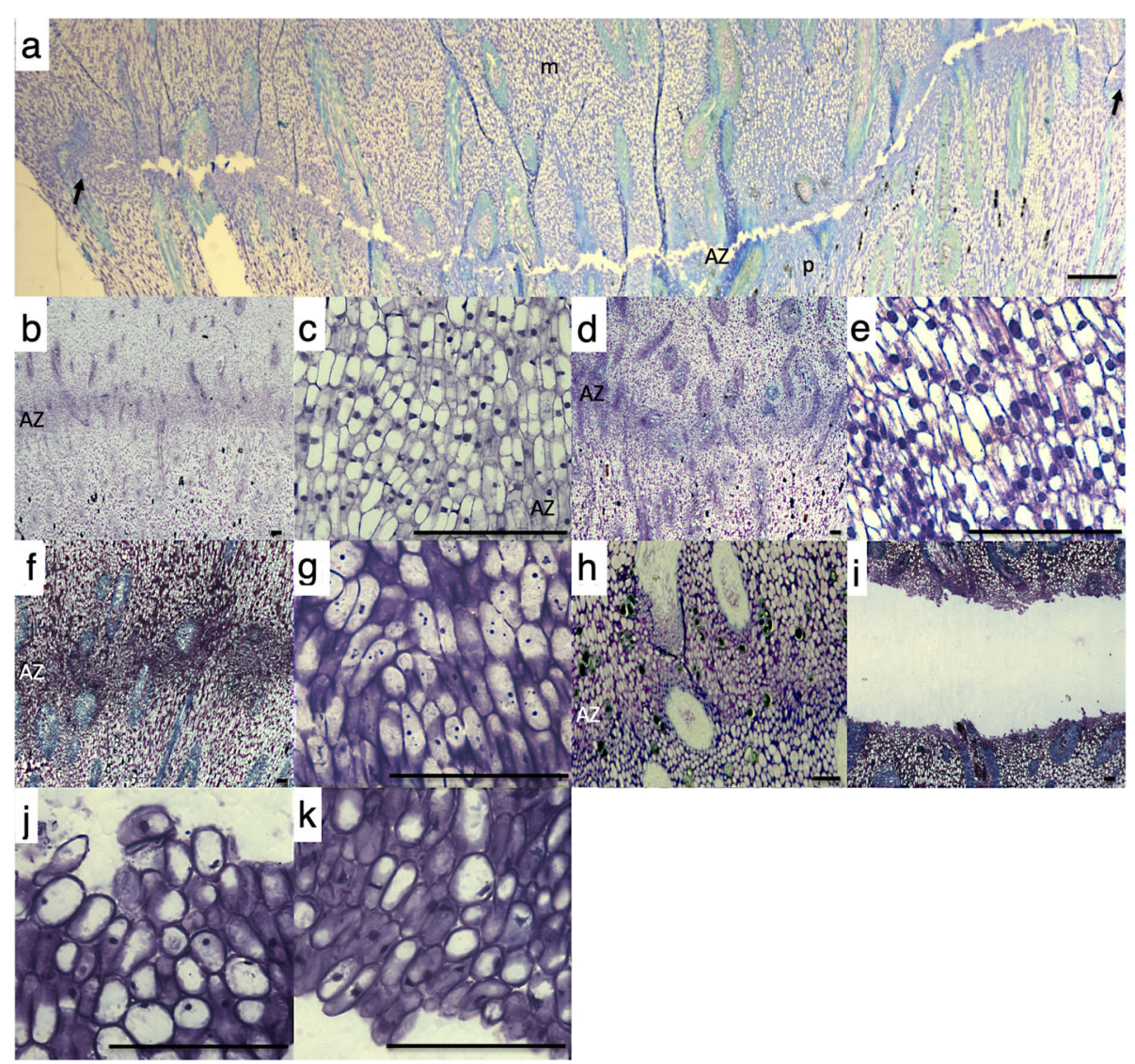

Fig. 1 Comparison of the abscission zone, mesocarp and pedicel tissues at the base of the oil palm fruit in response to ethylene and during natural abscission in the field. The mesocarp $(\mathrm{m})$ is above and the pedicel $(\mathrm{p})$ is below the abscission zone (AZ) in all photos. a cell separation occurs in the ripe fruit (150 DAP) primary AZ after $9 \mathrm{~h}$ of ethylene treatment, but only to a limited extent in the adjacent AZs which are difficult to discern (black arrows). $\mathbf{b}$ and $\mathbf{c}$ no cell separation is observed in the tissues (pedicel, mesocarp and AZ), at the base of 30 DAP fruit in the field, or treated with ethylene for $9 \mathrm{~h}$ ( $\mathbf{d}$ and $\mathbf{e})$. $\mathbf{c}$ and $\mathbf{e}$, Higher magnification view of AZ from 30 DAP fruit in the field and treated with ethylene for $9 \mathrm{~h}$ respectively. $\mathbf{f}$ and $\mathbf{g}$ No cell separation is observed in the tissues (pedicel, mesocarp and AZ) at the base of 120 DAP fruit in the field. $\mathbf{h} 160$ DAP AZ prior to cell separation and after cell separation (i) that occurred during natural abscission in the field. $\mathbf{j}$ Higher magnification view of 160 DAP fruit AZ cells separated on pedicel and on the mesocarp side (k) of AZ that underwent natural abscission in the field. Scale bars are $100 \mu \mathrm{m}$ 


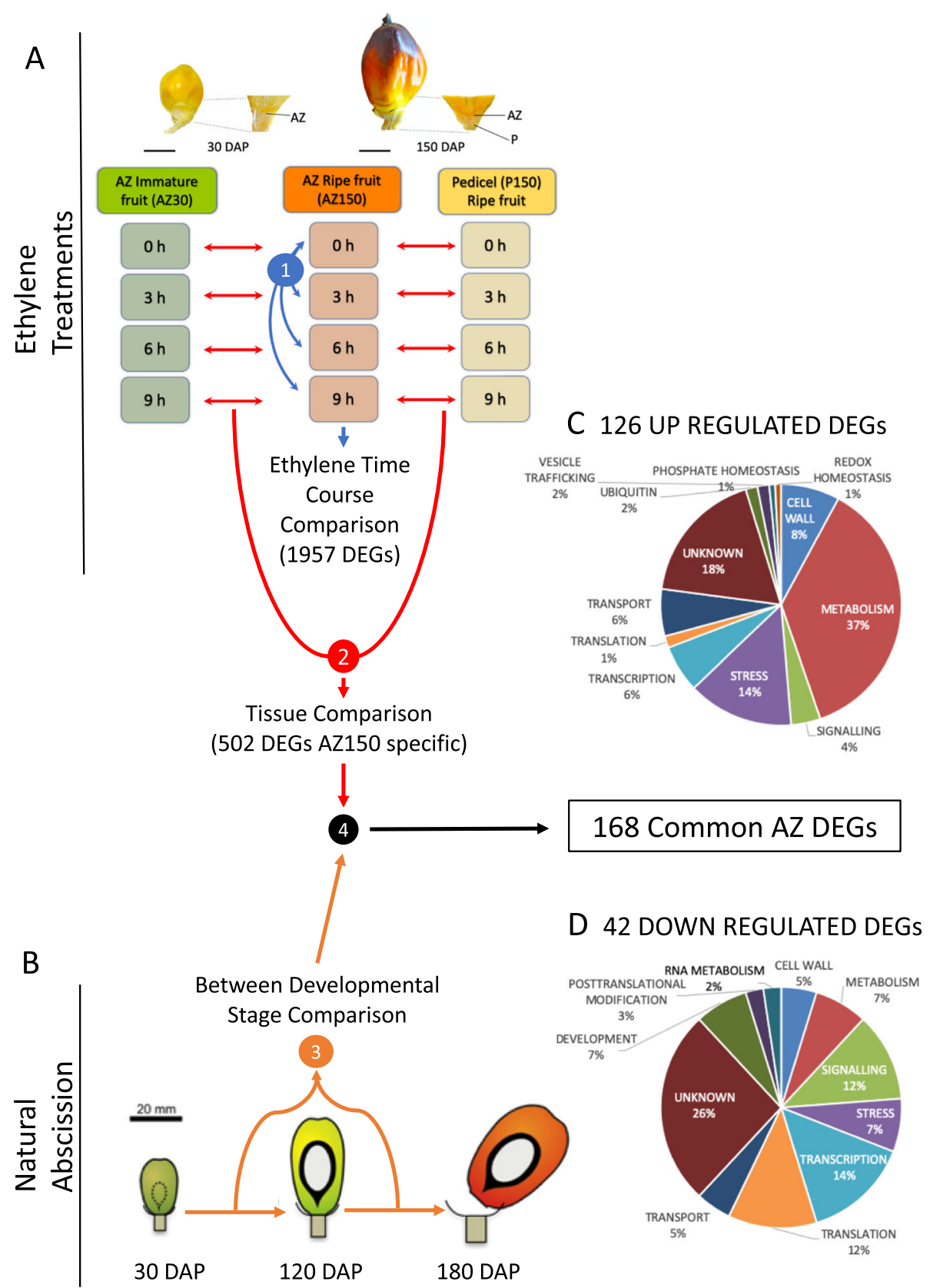

Fig. 2 A multi-scale comparative transcriptome analysis approach was used to screen for genes activated or repressed in the ripe fruit AZ during abscission. a We first used ethylene to induce abscission in ripe fruit, and compared the expression profiles of the ripe fruit AZ (AZ150) with that of adjacent pedicel tissue (P150) and immature fruit AZ (AZ30), in which no cell separation occurs under ethylene treatments. To screen for preferential ripe fruit AZ expression, differential expression in the AZ150 was first identified (blue arrows, screen step 1), then DEGs with similar profiles in the AZ30 and P150 were eliminated (red arrows, screen step 2). Candidate DEGs were retained when there was a statistical difference between their expression in the AZ150 DAP samples compared with the P150 DAP and AZ30 DAP for at least one time point ( $0 \mathrm{~h}, 3 \mathrm{~h}, 6 \mathrm{~h}$ or $9 \mathrm{~h})$. b A transcriptome developmental time course (30,120 and 160 DAP) of the AZ from fruit during natural abscission was then obtained (step 3) to provide a comparison with the DEGs found in the AZ during ethylene induced abscission (screen step 4) that resulted in the identification of 168 DEGs common to both ethylene induced and natural abscission (black arrow). c From these DEGs, 126 were up regulated and (d) 42 were down regulated in the AZ during abscission in both contexts

treated with ethylene at same time intervals) at each ethylene treatment time point (Fig. 2a). From this analysis, a total of 502 DEG candidates were retained based on their higher or lower expression level in AZ150 compared to that observed in both AZ30 and P150 (Supplementary Table 2). 
As a third step to screen for AZ genes involved in abscission, we analysed gene expression in the $\mathrm{AZ}$ of ripe fruit undergoing natural abscission in the field and aimed at finding genes with similar expression profiles between ethylene induced and natural abscission in the field (Fig. 2b). The study was conducted with samples from the AZ collected in the field at 30 DAP (Fig. 1b and c), 120 DAP (Fig. $1 \mathrm{f}$ and g), during which time no abscission was observed, and 160 DAP (h-k) collected from a fruit bunch where abscission was observed (Fig. $1 \mathrm{f}-\mathrm{k}$ ). A physical pull test revealed that none of the fruit from the 120 DAP spikelet could be removed when pulled, while the fruit from the lower (65\%) and upper portion $(92 \%)$ of the 160 DAP spikelet were easily removed and the fruit separated along the primary AZ (Fig. 3a, b and c). In addition, tissue samples were taken and confirmed that separation only took place in the AZ from fruit at 160 DAP spikelets, while no separation is observed in the $\mathrm{AZ}$ at 30 or 120 DAP (Fig. 1b, c, f, g, i-k).

A total of 168 DEGs were found to have expression profiles comparable during both ethylene induced and natural field abscission, including 126 up-regulated and 42 down-regulated genes in the $\mathrm{AZ}$ during abscission, and were retained for further analysis of processes and genes associated with abscission (Fig. 2c and d; Supplementary Table 3). Among the 168 DEGs, 34 had unknown annotations, while 134 candidate genes were assigned putative functions, and the most-represented functional classes included metabolism (49), followed by stress (21), transcription (14), cell wall (12) and signalling (10).

\section{Validation of abscission-related genes through a gene expression survey in the $A Z$ of a non-shedding oil palm variant}

To provide validation for functional roles of the 168 candidate genes identified to be involved in the abscission process, the expression profiles of a selected subset (23) were examined in the $\mathrm{AZ}$ of an individual oil palm (MTC180), previously shown to not shed its fruit [25]. While the AZ of the ripe fruit from MTC180 are differentiated with similar cellular characteristics as with individuals that shed their ripe fruit normally, MTC180 fruit remain on the trees and no natural abscission in the field was observed (Fig. 4 [25];). Our hypothesis was that the non-shedding character of this individual is due to perturbations in the gene expression network required for abscission to occur. We predicted that genes important for abscission would have the altered expression profiles in the non-shedding (MTC180) fruit AZ, compared with those observed in the AZ during natural abscission, and in response to ethylene induced abscission. A qRT-PCR analysis of $\mathrm{AZ}$ samples from normally ripening and shedding fruit, in comparison with the AZ from fruit that remain attached and are not shed was performed. The candidates selected all had comparable expression during both ethylene induced abscission and natural fruit abscission in the field, and had a range of annotations, including those related to the cell wall, metabolism, signal transduction, transcriptional regulation, stress, transport, auxin transport and response, redox homeostasis, and one unknown. From the 23 candidates
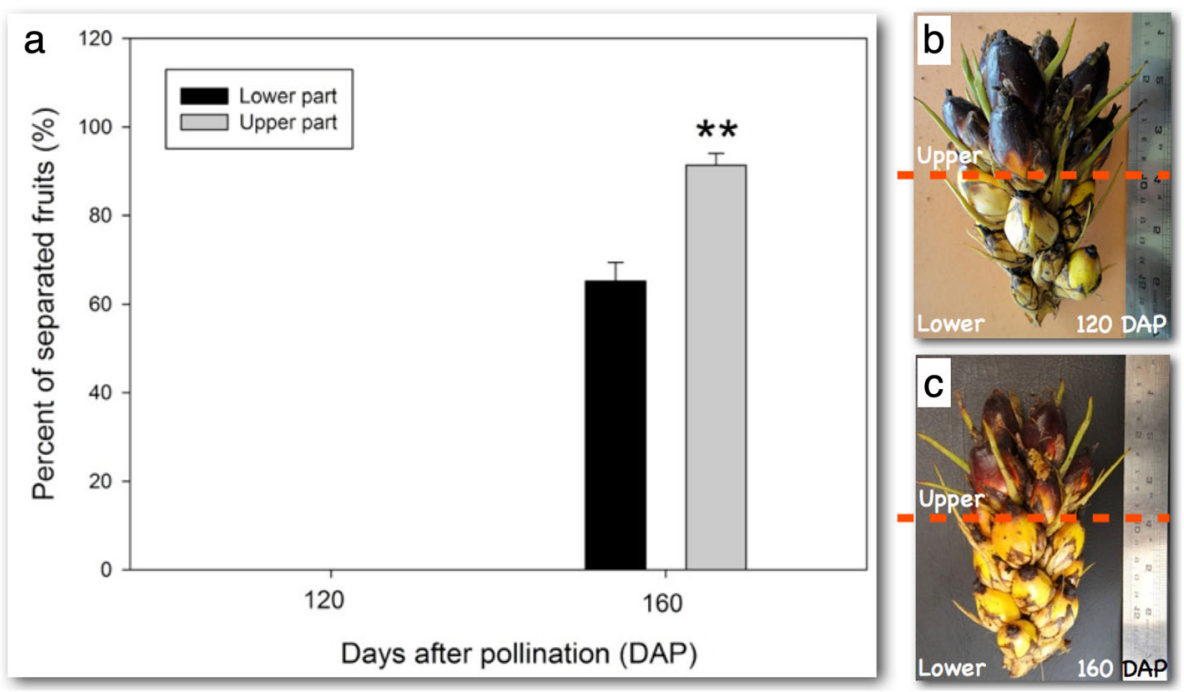

Fig. 3 Only ripe fruit in the field undergo natural abscission and ripening is unsynchronized within the spiketlet. a A test for loose fruit was performed to compare developing (b, 120 DAP) and ripe fruit (c, 160 DAP) in the field. The fruit on the spikelets were tested for looseness by pulling on the individual fruit. No loose fruit were found at 120 DAP, while loosened fruit were found at 160 DAP. While no difference was found within the spikelet for fruit at 120 DAP, the fruit from the upper half of the ripe fruit spikelet at 160 DAP separated more than the lower half. The expression profiles of the DEGs candidates was performed with the AZ from the fruit at 120 DAP when no loosening was observed and compared with the AZ from fruit where loosening was observed (160 DAP) 

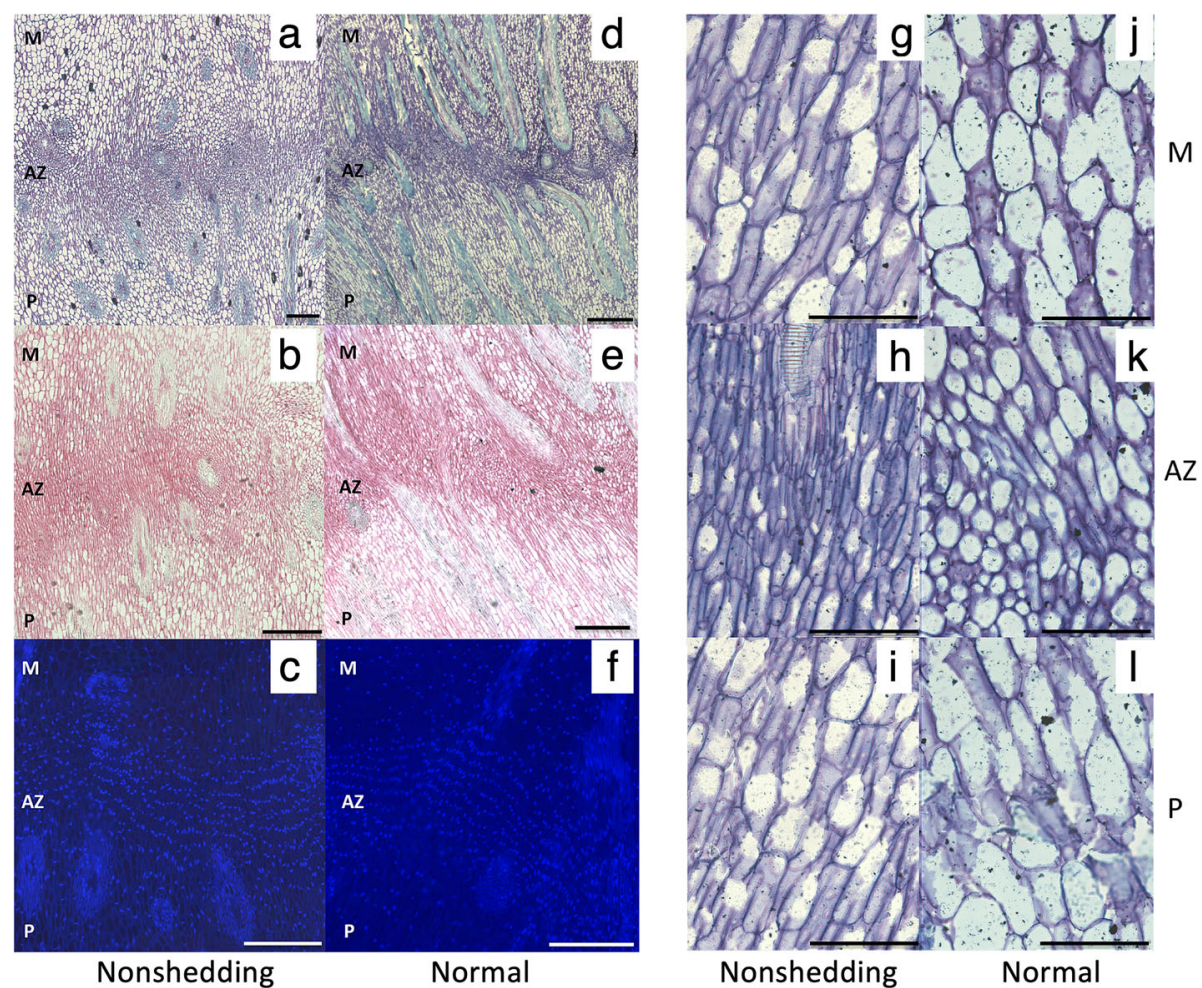

Fig. 4 No abnormalities are observed in the non-shedding MTC180 AZ that has characteristics of a functional AZ. A comparison of the fruit AZ of the nonshedding individual MTC180 (a-c) with that of a normal functional AZ in ripe fruit at 160 DAP (d-f) reveals fully differentiated AZ cell characteristics including aligned nuclei and small cytoplasmically dense cells, and no apparent abnormalities in the non-shedding AZ. Longitudinal sections were stained with toluidine blue (a, d, $\mathbf{g}-\mathbf{l})$, ruthenium red (b and e) and DAPI (c and f). M, mesocarp; AZ, abscission zone; P, pedicel; Scales bars are $100 \mu \mathrm{m}$ (a-f) and $50 \mu \mathrm{m}$ for (g-l)

selected, 17 of the candidates (72\%) had expression profiles in the AZ of non-shedding fruit that matched our predictions, i.e. altered expression profiles in the nonshedding fruit AZ compared to those observed during ethylene induced and natural abscission (Fig. 5; Supplementary Table 5). It should be noted that all the cell wall related transcript profiles matched our predictions, including those that encode PG4 and PGAZ1, PGAZ2, PMEI-like, Thaumatin-like, LAC7 and beta xylosidase. The transcripts for these proteins were detected at very low amounts in the non-shedding AZ compared with their amount found in AZ during the ethylene induced and natural abscission. Three of the four metabolic gene expression profiles also matched our predictions, including transcripts encoding Hydroxy-methylglutarylcoenzyme A reductase, Acyl-lipid thioesterase 3 (ALT3) and Beta-ureidopropionase. Two transcription factor transcripts encoding a BZIP and bHLH, were down regulated in the non-shedding AZ, while the transcript for EgERF105 was relatively high in the non-shedding AZ compared to during ethylene induced and natural abscission. Finally, two transcripts encoding signal transduction components including a serine/threonine protein kinase and HSL1, (HAESA-like leucine-rich repeat receptor kinase1), were detected in lower amounts in the non-shedding AZ. Such a high level of congruence further strengthens the potential roles that the 168 candidate genes play in the AZ during the abscission process.

AZ-specific genes expressed during ethylene induced and naturally ripe fruit abscission include genes involved in cell wall modification and degradation, as well as organ separation

Among the 134 annotated gene candidates, 12 genes encode proteins directly involved in the synthesis, modification or degradation of cell wall polysaccharides (Supplementary Table 3). Quite noticeably, half of them encode proteins related to pectin modification and degradation (EgPG4, EgPGAZ1, EgPGAZ2, EgPMEI, EgBXL2, EgLRX4). Among those, EgPG4 was previously found to be highly expressed in ripe fruit undergoing natural abscission [20]. The others relate to xyloglucan and mannan degradation (EgBGLC1 and EgMAN7, respectively), phenylpropanoid and lignin biosynthesis (EgLAC7, EgC4H/CYP73A5/REF3), callose biosynthesis (EgGSL1) and cell wall acidification (EgHA2). Other annotation categories had additional candidates closely linked to the cell wall, including A cystathionine betasynthase (CBS) family protein CBSX-2, a key redox sensor that directly regulates the activation of thioredoxins 


\begin{tabular}{|c|c|c|c|c|c|c|c|c|c|}
\hline \multirow{2}{*}{$\begin{array}{l}\text { Cat } \\
\mathrm{CW}\end{array}$} & \multirow{2}{*}{$\begin{array}{ll} & \text { Annotation } \\
\end{array}$} & \multirow{2}{*}{\begin{tabular}{|c|} 
contig \\
CL1Contig10800
\end{tabular}} & \multirow{2}{*}{\begin{tabular}{|c|} 
LOC \\
LOC105034919
\end{tabular}} & NA & ET & \multicolumn{2}{|c|}{ Normal Fruit AZ } & \multicolumn{2}{|c|}{ Non-S Fruit AZ } \\
\hline & & & & 30120 & 03 & IM & $\mathbf{R}$ & RNS & RNS \\
\hline CW & *EgPGAZ1 & Q1Contig6920 & LOC105056882 & & & 0.00 & 1.00 & 0.03 & 0.02 \\
\hline $\mathrm{cw}$ & *EgPGAZ2 & C1Contig9409 & LOC105056874 & & & 0.01 & 1.00 & 0.02 & 0.05 \\
\hline $\mathrm{cW}$ & *PMEI-like & CL1Contig10995 & LOC105041092 & & & 0.02 & 1.00 & 0.01 & 0.00 \\
\hline $\mathrm{cw}$ & *Thaumatin-like (Osmotin-like) & C.1Contig1963 & LOC105033331 & & & 0.03 & 1.00 & 0.00 & 0.00 \\
\hline $\mathrm{cW}$ & *eglaC7 & C1Contig10326 & LOC105052147 & & & 0.15 & 0.95 & 0.01 & 0.11 \\
\hline cow & *Beta xylosidase & O1Contig?306 & 106105039923 & & & 0.86 & 1.00 & 0.03 & 0.03 \\
\hline MT & ${ }^{*}$ Hydroxy-methylglutaryl-coenzyme A reductase & CL1Contig24608 & LOC105036971 & & & 0.31 & 1.00 & 0.05 & 0.03 \\
\hline MT & *Acyl-lipid thioesterase 3 (ALT3) & Q1Contig19474 & LOC105054001 & & & 0.57 & 1.00 & 0.25 & 0.30 \\
\hline MT & *Beta-ureidopropionase & CL1Contig15784 & LOC105054031 & & & 0.55 & 1.00 & 0.32 & 0.34 \\
\hline MT & Aromatic-ring hydroxylase-like & C.1Contig11041 & LOC105043756 & & & 0.44 & 1.00 & 0.63 & 0.90 \\
\hline ST & *Serine/threonine protein kinase & Q.1Contig11148 & LOC105054206 & & & 0.30 & 1.00 & 0.22 & 0.22 \\
\hline RH & EgCBSX1 & C.1Contig6450 & LOC105050145 & & & 1.00 & 0.81 & 0.51 & 0.88 \\
\hline TF & *BZIP transcription factor & CL1Contig11193 & LOC105039935 & & & 0.98 & 1.00 & 0.36 & 0.28 \\
\hline TF & ${ }^{*}$ bHLH transcription factor (CIB1) & C.1Contig9735 & LOC105058752 & & & 0.28 & 1.00 & 0.02 & 0.03 \\
\hline $\mathrm{TF}$ & *EgERF105 & CL1Contig10002 & LOC105043733 & & & 0.78 & 0.52 & 0.60 & 1.00 \\
\hline ST & ${ }^{*}$ EgHSL1 & C.1Contig16961 & LOC105051708 & & & 1.00 & 0.41 & 0.08 & 0.10 \\
\hline $\mathrm{s}$ & EgYLS9 & CL1Contig1374 & LOC105060420 & & & 0.28 & 0.58 & 0.40 & 1.00 \\
\hline $\mathrm{s}$ & ${ }^{*} \mathrm{EgHIS1}$ & C.1Contig4234 & LOC105059363 & & & 1.00 & 0.76 & 0.05 & 0.08 \\
\hline TP & *Sulphate anion transporter & Q.1Contig9617 & LOC105043754 & & & 0.66 & 1.00 & 0.24 & 0.29 \\
\hline AUX & Auxin efflux carrier 2 family protein (PIN-LIKES) & Q.1Contig25900 & LOC105046029 & & & 0.02 & 0.03 & 0.19 & 1.00 \\
\hline AUX & Auxin responsive protein (IAA17-like) & C1Contig1153 & LOC105040857 & & & 1.00 & 0.62 & 0.51 & 0.44 \\
\hline $\mathrm{u}$ & EgTRFL2 & C.1Contig6389 & LOC105044389 & & & 0.19 & 0.28 & 0.56 & 1.00 \\
\hline
\end{tabular}

Fig. 5 A comparison of the expression profiles of selected gene candidates in the AZ during ethylene induced abscission (ET), natural abscission (NA) that occurs in the field and in the AZ fruit that remain attached to the fruit bunch and are not shed (Non-S). The NA column includes samples from 30, 120 and 160 DAP. The ET column includes profiles of statistically significant candidates expressed preferentially in the AZ during ethylene induced abscission (0,3 h, $6 \mathrm{~h}$ and $9 \mathrm{~h}$ of treatment). Expression profiles of many candidates in the AZ during ethylene induced and natural abscission (column ET and NA) are opposite to that found in the non-shedding fruit AZ. Normal backcross (IM and R) eventually shed their fruit, while the non-shedding backcross (RNS columns) do not. Results of the expression profile from qPCR shown by the heat map with the highest peak of expression calculated as 1. CW, Cell Wall; MT, Metabolism; TF, Transcription Factor; AUX, auxin related; TP, Membrane Transport; ST, Signal Transduction. IM, Immature Fruit; R, Ripe fruit; RNS, Ripe Non-Shedding fruit)

and regulate enzymes involved in lignin polymerization and cell wall thickening during anther dehiscence in Arabidopsis [26, 27], in addition to the synthesis of cell wall precursors (EgMIPS2) and the synthesis of cell wall bound ferulic acid (EgREF1), which may contribute to the different levels of ferulic acid content between dicotyledon and monocotyledon plants [28].

Strikingly, among those cell-wall related genes, five encode proteins with similarities to those identified with functional roles during Arabidopsis floral organ

Table 1 DEGs with similarities to genes with functional roles in cell separation events

\begin{tabular}{|c|c|c|c|c|c|c|}
\hline Contig Name & Eg Locus & $\begin{array}{l}\text { TAIR9 } \\
\text { accession }\end{array}$ & Best manual annotation & $\begin{array}{l}\text { Gene } \\
\text { name }\end{array}$ & Reference & Separation event \\
\hline CL1Contig6920 & LOC105056882 & AT3G57510 & Endo-polygalacturonase (ADPG1/PGDZAT) & EgPGAZ1 & {$[29,30]$} & $\begin{array}{l}\text { Arabidopsis anther dehiscence, } \\
\text { silique dehiscence, seed } \\
\text { abscission }\end{array}$ \\
\hline CL1Contig9409 & LOC105056874 & AT3G57510 & Endo-polygalacturonase (ADPG1/PGDZAT) & EgPGAZ2 & {$[29,30]$} & $\begin{array}{l}\text { Arabidopsis anther dehiscence, } \\
\text { silique dehiscence, seed } \\
\text { abscission }\end{array}$ \\
\hline CL1Contig10326 & LOC 105052147 & AT3G09220 & Laccase 7 & EgLAC7 & {$[5]$} & $\begin{array}{l}\text { Arabidopsis floral organ } \\
\text { abscission }\end{array}$ \\
\hline CL1Contig20303 & LOC 105040138 & AT5G66460 & $\begin{array}{l}\text { Endo-beta-mannase 7/Glycosyl hydrolase } \\
\text { superfamily protein/MANNANASE7 }\end{array}$ & EgMAN7 & {$[31]$} & Arabidopsis silique dehiscence \\
\hline CL1Contig16961 & LOC 105051708 & AT1G72180 & Receptor-like protein kinase HSL1 & $\begin{array}{l}\text { EgHSL1/ } \\
\text { CEPR2 }\end{array}$ & {$[32]$} & $\begin{array}{l}\text { Arabidopsis floral organ } \\
\text { abscission }\end{array}$ \\
\hline CL1Contig6450 & LOC105050145 & AT4G36910 & $\begin{array}{l}\text { Cystathionine beta-synthase (CBS) family } \\
\text { protein }\end{array}$ & $\begin{array}{l}C B S \times 1 / \\
L E J 2\end{array}$ & {$[26,27]$} & Arabidopsis anther dehiscence \\
\hline CL1Contig17462 & LOC 105059537 & $\begin{array}{l}\text { AT5G41410/ } \\
\text { Os05g38120 }\end{array}$ & Homeobox protein BEL1 homolog / SH5 & EgBEL1 & {$[33]$} & Rice seed shattering \\
\hline
\end{tabular}


abscission, anther dehiscence, silique dehiscence or seed abscission including: sequences similar to ADPG1, MANNANASE7 (MAN7), LACCASE7 (LAC7), cystathionine beta-synthase (CBS) family protein (CBSX1) (Table 1 [29-31]. Our candidate gene list also includes a HEASA-like leucine-rich repeat receptor kinase, unrelated to cell-wall metabolism, but shown to be involved in Arabidopsis floral organ abscission [32]. In addition, a BEL1-like transcription, similar to $\mathrm{SH} 5$ in rice, which induces grain shattering through the control of abscissionzone development and the inhibition of lignin biosynthesis, was also identified [33]. These findings validate our approach used to identify AZ genes with functional roles during oil palm ripe fruit abscission, and provide evidence for common mechanisms related to cell separation between monocots and dicots.

\section{Hormone pathways are activated in the AZ during abscission}

From the comparison between ethylene induced and natural abscission, we observed a number of ethylene related genes with common transcription profiles in both contexts. Genes identified encode proteins involved in ethylene biosynthesis (1-AMINOCYCLOPROPANE-1CARBOXYLATE OXIDASE5, ACO5), perception (ETHYLENE INSENSITIVE4, EIN4), mobilization of the ethylene precursor 1-aminocyclopropane-1-carboxylic acid (ACC) lysine histidine transporter (LHT1) [34];) and ethylene response factors (ERF18 and RAP2.2), in addition to the transcription factors related to ethylene response including NAC6, MYC2, and EIN3 (Supplementary Table 3). Interestingly in Arabidopsis, the transcription factor NAC6 regulates ACO5 and cell wall modifying enzyme genes in an ethylene dependent manner, while MYC2 and EIN3 were found to modulate ethylene and jasmonate (JA) activity antagonistically [35, 36]. The genes that encode for ACO5, EIN4, NAC6, MYC2 and RAP2.2 were all upregulated, while those for EIN3 and ERF18 were down regulated during abscission. In addition to ethylene, transcripts related to JA biosynthesis were also identified, including ALLENE OXIDE CYCLASE 3 (AOC3), which increases, and LIPOXYGENASE5 (LOX5 [37];), which decreases during abscission. The presence of key players in the synthesis, perception, signalling and response of ethylene among the candidate genes further supports an important role for ethylene during abscission, provides evidence for possible interactions between ethylene and JA, validates the multi-scaled screening approach and gives weight to the other candidates identified.

Auxin related transcripts were also found common to both ethylene induced and natural abscission. Transcripts included those encoding for proteins involved in auxin homeostasis (CATALASE 2, CAT2.1 and CAT2.2
[38];), and/or transport (PIN-LIKES 6, PILS6 [39];; SNX1 [40];; CLC2 [41];) and conjugation (GH3.5/WES1 [42];) were identified, as well as auxin-dependent transcription (IAA27/PAP2 [43];) and auxin/ubiquitin mediated proteolysis (SKP2A [44];). The transcripts CAT2.1, CAT2.2, PILS6, SNX1, GH3.5/WES1 and SKP2A increase in the AZ during abscission, while CLC2 and IAA27 decrease. Taken together, these observations provide evidence of the importance of hormone-related transcriptional programs activated during oil palm ripe fruit abscission.

\section{AZ abscission-specific genes fingerprinted pathways related to senescence, nutritional stress, nutrient recycling, energy and oxidative stress}

Our analysis identified genes known to be up-regulated at the onset of senescence, involved in key processes including macromolecule degradation, nutrient salvage and translocation, as well as detoxification and defence. Key senescence markers identified include the SENESC ENCE-ASSOCIATED GENE 15/EARLY RESPONSIVE TO DEHYDRATION STRESS 1 (SAG15/ERD1) gene and the senescence-inducible chloroplast STAYGREEN1 (SGR1) gene [45-47]. Another senescence related gene identified, $A M Y 1$ that encodes $\alpha$-amylase1, is a stressinduced enzyme secreted extracellularly in Arabidopsis leaves possibly involved in starch degradation after cell death [48]. Key transcriptional regulators known to be directly or indirectly involved in the regulation of senescence including ATAF1, RAP2.4 and MYC2 were also identified [49-51]. The photoassimilate-responsive gene PAR1, which encodes a PR-like protein and increases in response to high levels of soluble sugars [52], suggests a metabolic transition from anabolism to catabolism occurs during abscission. Genes were identified that encode glutamate dehydrogenase (GDH), alanine aminotransferase (AlaAT2), 3-methylcrotonyl-CoA carboxylase (MCCB), the alpha-subunit (E1A2) of branched-chain ketoacid dehydrogenase complex (BCKDC) and the Lysine-Ketoglutarate Reductase/Saccharopine Dehydrogenase bifunctional enzyme (LKR/SDH), all key enzymes involved in the catabolism of free amino acids (i.e. alanine, leucine, lysine and glutamate). Markers of nitrogen and phosphate starvation were also found, including a down-regulated major nitrate transporter NRT1 and upregulated phosphocholine phosphatase PECP1 respectively $[53,54]$. In addition, the analysis identified a gene similar to PYD3, which encodes beta-ureidopropionase, an enzyme that catalyses a late step in pyrimidine degradation, and functions in the recycling of nitrogen from nucleobases to general nitrogen metabolism [55].

A dramatic switch in energy metabolism during abscission is suggested by the presence of a key BZIP53 TF involved in primary metabolism reprogramming under 
low energy stress [56]. In addition, genes for enzymes that provide alternative substrates for TCA cycle and oxidative phosphorylation including adenosine monophosphate (AMP) deaminase (FAC1) and adenylosuccinate synthetase $(A D S S)$ were identified. There were also key glycolytic genes up-regulated, including fructose biphosphate aldolase (FBA6) and the phosphofructokinases, PFK2, PFK3 and PFK5. In addition, genes encoding pyruvate decarboxylases ( $P D C 2$ and $P D C 4$ ), aldehyde dehydrogenase $(A L D H 2 B 4)$ and alcohol dehydrogenase $(A D H 1)$, key markers of intense glycolytic activity derived towards fermentative metabolism (ethanol and acetate) for energy supply, were also identified.

We found evidence for a major switch in redox control in the AZ during oil palm ripe fruit abscission. Firstly, the transcriptional activation of key players of reactive oxygen species (ROS) homeostasis in peroxisomes were identified including two genes encoding ROS-scavenging catalase homologs to Arabidopsis CAT2, a key mediator of cell redox homeostasis shown to coordinate salicylic acid (SA) repression of auxin accumulation and JA biosynthesis during plant defence [57]. In addition, a gene for a peroxisomal glycolate oxidase (GOX), a photorespiratory enzyme that may also serve as an alternative source for the production of $\mathrm{H}_{2} \mathrm{O}_{2}$ during biotic stress was identified [58]. Secondly, evidence for a key glutathione biosynthetic gene (Glutamate-cysteine ligase/ROOT MERISTEMLESS 1, GSH1/RML1) as well as aldehyde dehydrogenase $(A L D H 3 H 1)$ putatively involved in detoxifying aldehydes generated by lipid peroxidation were identified $[59,60]$. Thirdly, key markers of adaptation to oxidative stress in plastids were identified including the DnaJ chaperone J8, a nuclear encoded soluble protein found in the chloroplast stroma that accumulates in response oxidative stress, and the stress-induced RELA/ SPOT homolog 3 (RSH3, LOC105041854) involved in ppGpp stress signalling in plastids [61, 62]. Finally, evidence for a parallel metabolic adaptation to intense oxidative stress includes the upregulation of transcripts for fructose-bisphosphate aldolase (FBA6) and alternative oxidase $(A O X 1)$, indicative of adaptation to oxidative stress of glycolytic and respiratory activities, respectively $[63,64]$.

\section{Discussion}

\section{Common organ abscission genes and processes of eudicots and monocots}

Monocot and eudicots phylogenies have evolved mechanisms for fleshy fruit abscission to disperse seeds, but how these mechanisms differ between taxa is unclear. In the current study we used a multi-scale transcriptome analysis to compare the ripe fruit AZ, pedicel, and immature fruit AZ treated with ethylene, AZ during natural abscission and $A Z$ of non-shedding fruit samples, to identify a robust list of core genes and processes that function in the AZ during fleshy fruit abscission of this monocot.

Seed dispersal strategies of higher plants can be divided into three major categories; seed shattering (e.g. domesticated cereal crops of the Poaceae), dry fruit dehiscence (i.e. pod shattering of Arabidopsis and many species of the Brassicaceae and Fabaceae), and fleshy fruit abscission (e.g. tomato as the most studied dicot model $[4,65] ;$ ). While both seed shattering and fleshy fruit abscission occur through cell separation events in the $\mathrm{AZ}$ at the base of the fruit, dry fruit dehiscence involves two cell separation events, in the dehiscent zone (DZ) in the valve margin, and in the AZ at the base of the seed [65-67]. Interestingly, despite anatomical differences between these different dispersal mechanisms, convergent evolution has been observed [67-70]. For example, qSH1 and RPL (REPLUMLESS), orthologs of a BEL1-type homeobox transcription factor, function in the grain $\mathrm{AZ}$ of rice and the $\mathrm{DZ}$ of Arabidopsis dry fruit respectively $[68,71]$. Another example are orthologs of the Sh1, which encode YABBY transcription factors that function in the seed AZ of sorghum, rice and maize and were selected in parallel during domestication for the non-seed shattering trait [70]. In the fruit AZ of the oil palm, we found genes that are expressed with similarities to those with known functional roles during dry fruit dehiscence of Arabidopsis, in addition to, BEL1 (Table 1) with similarity to the those expressed in the seed AZ of the cereals and the DZ of Arabidopsis. This suggests conserved mechanisms of oil palm fruit abscission include those found related to dicot and monocot AZ differentiation, in particular, those related to Arabidopsis dry fruit silique separation (Table 1).

Within the group of candidates we found expressed in the oil palm fleshy fruit AZ, five candidates have similarities to genes that function during Arabidopsis silique dehiscence (MANNANASE7, MAN7, and ADPG1/ PGDZAT, renamed EgMAN7, EgPGAZ1 and EgPGAZ2 respectively) and floral organ abscission (LAC7 and a leucine-rich repeat receptor kinase similar to HSL1, renamed EgLAC7 and EgHSL1 respectively), which again provides evidence that some established mechanisms of cell separation in the $\mathrm{DZ}$ and $\mathrm{AZ}$ for model dicots are conserved for this fleshy fruit monocot [30-32, 72]. In particular, we again found key genes for dry fruit dehiscence. For example, MAN7, which encodes an endobeta-mannase, functions in Arabidopsis and Brassica napus silique dehiscence, with expression in both vegetative and reproductive organs, with high expression in the Arabidopsis siliques at a stage just prior to the initiation of dehiscence [31, 73]. ADPG1 also functions in Arabidopsis silique dehiscence, while expression is more specific to the silique $\mathrm{DZ}$ and seed $\mathrm{AZ}$, and functions in 
both processes [30]. These results provide evidence that some cell separation mechanisms in both dry fruit dehiscence and fleshy fruit abscission are conserved, or have evolved in parallel. Interestingly, the combination of mutations in MAN7 and ADPG1 increases the indehiscence phenotype, demonstrating the combined function of different classes of cell wall modifiers is necessary for cell separation [30, 31]. Indeed, we identified other transcripts that encode proteins similar to Arabidopsis sequences with functions related to cell wall polymer modifications including those for pectin, lignin, xyloglucan and callose [5, 30, 31, 74-77]. The Arabidopsis LRX4 is involved in cell wall and plant development related to pectin, while the Arabidopsis BXL2 is very similar to BXL1, both of which appear to be involved in polar secretion of pectinaceous mucilage from the seed coat epidermis [74, 75]. In addition, a transcript similar to $\mathrm{H}[+]$-ATPase 2 with possible roles in cell wall acidification mediated by receptor kinase activity was also found [57, 78, 79]. These gene functions correspond closely to processes observed previously in the oil palm ripe fruit $\mathrm{AZ}$ during abscission. For example, AZ cells undergo polarized oriented cell wall building activity, which culminates with a decrease in methylesterified homogalacturonan HG (JIM5 signal increases) during abscission in a polarized manner [23]. Furthermore, two gene candidates associated with vesicle trafficking were also identified, which could be involved in auxin related transport, secretion and/or recycling of cell-wall components as found in other abscission systems [80-84]. In addition, changes in the cation environment were also observed in the oil palm AZ during fruit abscission [23], while $\mathrm{pH}$ changes are important for $\mathrm{AZ}$ function during tomato flower abscission [85]. Finally, a special role of lignin structure in Arabidopsis has been identified [5]. A specific lignin brace structure is found in the AZ cells of the separated organ, and acts to localize cell wall breakdown and spatially limit to abscising cells. In the current study, we found several lignin related transcripts which encode lignin biosynthesis and polymerization enzymes including LAC7, C4H and CBSX-2 (Supplementary Table 3). In Arabidopsis, $L A C 7$ is expressed specifically in the AZ cells of the separated organ. In the oil palm fruit, we found $L A C 7$ expression to be especially high in the AZ of ripe fruit that are separating (Fig. 5), which suggests lignin biosynthesis is also important for abscission. In transcriptome study with citrus, lignin biosynthesis transcripts were also found to be expressed specifically in the Starch-rich Area (SA) within the fruit abscission zone (AZ-C), which are also cells undergoing separation [86]. Collectively, lignin appears to be an important feature for a variety of organ abscission contexts, including Arabidopsis floral organs, citrus fruit and oil palm fleshy fruit.
The current study corroborates the importance of pectin related changes during abscission by the identification of two additional PGs (EgPGAZ1 and EgPGAZ2) with similarity to the Arabidopsis ADPG1 that is essential for silique dehiscence [30]. In addition, a transcript for a pectinesterase (EgPMEI) has similar profiles to the three PGs in the AZ during ethylene and naturally induced abscission, with a consistent increase of transcript amounts. Indeed, PG transcripts and activity increase in various species during the abscission process, and can be induced by ethylene or inhibited by auxin [87-92]. In tomato, there is a single PG transcript, pTOM6, expressed during fruit ripening [93-95], while four other PGs (TAPG1, TAPG2, TAPG4, and TAPG5) are expressed in the flower and leaf AZ $[89,90,96]$. In oil palm, EgPG4 is highly expressed in the mesocarp during ripening and induced in the AZ in response to ethylene [20]. In contrast, EgAZPG1 and 2 are specific to the AZ (Supplementary Table 6). Similar to EgPG4, EgPMEI is also expressed in the mesocarp so may also function during mesocarp ripening or provide coordination between the ripening mesocarp and AZ function during abscission. As discussed above, pectin related transcripts encoding beta-xylosidase and a leucine-rich repeat extensin-like protein were also found to be highly expressed during the abscission process suggesting other important pectin modifications involved in cell separation. The main type of pectin in primary walls and the main constituent of the middle lamella is $\mathrm{HG}$, a galacturonic acid polymer that exists in both methylesterified, less methylesterified and unmethylesterified forms [97]. The consequence of PME activity includes not only the demethylesterification of HG, but also the generation of methanol and a decrease in $\mathrm{pH}$ [98]. Complete demethylesterified HG increases stiffness in the cell wall due to calcium crosslinking of adjacent $\mathrm{HG}$ molecules, while a $\mathrm{pH}$ decrease can provide more optimal conditions for hydrolysis by PG. In addition, an increase in demethylesterified HG may be more easily hydrated and lead to cell wall loosening [98]. Indeed, the current model is that PME demethylesterifies HG, which subsequently is more susceptible to PG hydrolysis that could result in cell wall loosening [99]. Finally, combined PME and PG activities could release specific signalling oligogalacturonides, and in the case of the oil palm, could be a potential signal that originates from the primary AZ for activation of cell separation in the adjacent AZs as previously proposed [19].

Hormones, in particular ethylene (promotes) and auxin (inhibits), are well known to be involved in organ abscission, including Arabidopsis floral organ abscission and tomato flower and fruit abscission [4, 100, 101]. For oil palm ripe fruit abscission, both ethylene and auxin are known to function as inducer and inhibitor 
respectively $[19,20]$. In the current study, we found a number of hormone related transcripts, including those related to ethylene, auxin and JA pathways, with differential expression in the AZ during abscission. These results corroborate the importance of these pathways and suggests widespread conservation of function during abscission for these hormones [4].

The IDA-HAE-HSL2 (INFLORESCENCE DEFICIEN T IN ABSCISSION- HAESA- HAESA-LIKE2) signalling pathway discovered in Arabidopsis has become a significant focus of research $[6,102,103]$. The pathway involves a peptide ligand-receptor system that consists of the secreted peptide IDA encoded by the IDA gene, and the two leucine-rich repeat (LRR) receptor-like kinases (RLK) including HAE and HSL2. Both ida and hae hsl2 mutants retain their floral organs, while overexpression of the IDA gene reverts the ida mutant to the wild-type abscission phenotype, and overexpression in the wildtype of either IDA or IDA-LIKE (IDL) gene family members results in early abscission. There is currently a debate whether the IDA-HAE-HSL2 signalling pathway functions in other species and organs such as leaves or fruit. Our previous work provided evidence that the IDA and HSL-like genes are expressed in the oil palm fruit $\mathrm{AZ}$, and that the IDA peptide enhances cell separation and abscission in the oil palm fruit AZ [104, 105]. In the current study, we show that while a HSL1-like transcript normally decreases in the AZ during both ethylene induced and natural abscission, it is detected at even lower amounts in the non-shedding AZ, which corroborates what was observed previously [104]. This provides further evidence that the IDA-HAE-HSL2 pathway functions in the AZ during oil palm ripe fruit abscission, and appears to be a conserved signalling pathway for both dicot and monocot organ abscission.

The AZ specific transcriptome contains the transcriptional signature of a large metabolic rerouting associated with a senescence-like program during abscission.

Senescence and organ abscission are both regulated by ethylene, and common transcriptional controls have been found to coordinate the timing of the two process with floral organs of Arabidopsis [106]. The transcriptome survey of the AZ fingerprinted senescence marker genes and specific transcriptional regulators. Among senescence related markers, the SAG15/ERD1 gene encodes the regulatory subunit of the ATP-dependent plant caseinolytic protease (Clp) complex involved in the degradation of accumulated and misfolded chloroplast proteins, while SGRlencodes an Mg-dechelatase that represents a first step of the chlorophyll catabolic pathway and a key transcriptional regulation point of senescence-related pigment loss. In addition, the ATAF1 NAC TF serves as a core transcriptional activator of senescence by coupling stress-related signalling with photosynthesis- and senescence-related transcriptional cascades [49]. The RAP2.4 DREB transcription factor plays a key role in modulation of the senescence cascade and controls cell dedifferentiation in response to wounding [50], while MYC2 is a key transcription factor involved in JA-induced senescence processes such as chlorophyll degradation [51]. The transcriptome survey of the AZ also fingerprinted many genes known to be up-regulated at the onset of senescence, i.e. those related to proteolytic and free amino acid catabolic activities, carbon, nitrogen and phosphate salvage and translocation, as well as those involved in alternative routes for energy supply or adaptation to oxidative stress [107].

The identification of certain genes may reflect an intense proteolytic activity in the AZ, either through autophagy or proteasome mediated processes. Indeed, several genes associated with proteolytic activity were identified including a ubiquitin-protein transferase, a RING/U-box superfamily protein, an F-box/RNI-like superfamily protein and a cysteine proteinase superfamily protein. Associated with this senescence-related proteolytic activity, asparagine may be a major transport compound used for organic nitrogen reallocation to other tissues given that a gene for glutamine-dependent asparagine synthase (ASN1) was also identified [108]. Interestingly, phosphate-starvation generally induces reduction of the membrane phosphatidylcholine content to provide an internal phosphate source while replacing membrane phospholipids by galactolipids, a process termed membrane lipid remodelling. Abscission-related phosphocholine phosphatase PECP1 is a major player in this process in Arabidopsis, induced by starvation and involved in the liberation of inorganic phosphate Pi from intracellular sources [109]. In this context, genes for plasma membrane phosphate transporters PHT1 and PHT5 that may facilitate translocation of large Pi amounts released by PECP1 activity towards other tissues were also identified [110, 111]. While FAC1 catalyses the hydrolytic deamination of AMP to IMP (inositol monophosphate) ADSS is involved in the reverse reaction, which suggests a futile purine nucleotide cycle that could produce fumarate, and purine nucleotides that serve as an anapleurotic substrate to fuel the TCA cycle.

A switch in energy metabolism apparently occurs during abscission. In Arabidopsis, the BZIP53 TF promotes dark-induced senescence and participates in the transcriptional reprogramming of amino acid metabolism during the dark-induced starvation response, by triggering accumulation of specific proteins including ASN1 and amino acid catabolic genes. The BZIP53 TF acts downstream of SnRK1 (Snf1-RELATED KINASE1), and specifically coordinates the expression of genes involved in branched-chain amino acid catabolism, which also 
constitutes an alternative mitochondrial respiratory pathway that is crucial for plant survival during starvation [112]. A similar function in the oil palm fruit could explain the large up-regulation of amino acid catabolic pathways, producing organic acids that may be directly used to funnel TCA and oxidative phosphorylation. In this way, one may note that the energy yield, i.e. ATP production, from branched-chain amino acids (leucine, isoleucine, and valine) and lysine catabolism is particularly high, close to that measured with the oxidation of glucose as a substrate [113]. Furthermore, a futile cycle involving AlaAT and GDH, both detected in the present survey, that could mobilize carbon from alanine toward energy production, has been recently described in plants recovering from low energy stress [114]. Pyruvate produced by the reverse reaction of AlaAT is funnelled to the TCA cycle, while deaminating GDH regenerates, reducing equivalent (NADH) and 2-oxoglutarate to maintain the cycle function.

The transcriptional signatures detected in AZ during abscission for both an active TCA and oxidative phosphorylation as well as fermentative pathway (PDC2, PDC4, ADH1) may be puzzling at a first sight. However, acetate production could be independent of oxygen-limiting conditions, as recently demonstrated in Arabidopsis under drought response where it serves to stimulate the JA signalling pathway to confer stress tolerance [115]. The acetate pathway could also presumably occur under normoxia conditions in the AZ of oil palm fruits. In this way, one may note that ATP-dependant enzymes such as the cytosolic PFK2, the plastidial isoform PFK5, as well as invertase INV1 are transcriptionally induced during abscission rather than their inorganic pyrophosphate-dependent enzyme counterparts, respectively PFP and sucrose synthase, whereas these latter are assumed to be the preferred isoforms under hypoxic conditions [116]. Rather than by oxygen-limiting conditions, induction of the acetate pathway could be hormonally controlled through ethylene and the TF RAP2.2 transcriptional cascade [117].

Overall, how these large metabolic changes are linked to the abscission processes in the AZ are largely unknown, but based on our results, we can conclude that the transcriptional activity in the AZ appear to promote major metabolic transitions both spatially and temporally during ripe fruit abscission. A metabolic transition from anabolism to catabolism before controlled cell death could enable the recycling of major cellular components and nutrient redistribution to other tissues or oxidation towards energy production during the abscission developmental program. Such a program could be triggered by environmental stimuli such as nutrient limitation, i.e. carbon and nitrogen compound shortage caused by phloem flux arrest, or/and by internal hormonal factors (ethylene, JA, ABA). A recent report provided a link between metabolism and the mechanisms of auxin and ethylene regulated abscission [118]. The report demonstrated that auxin regulates sucrose transport during rose petal abscission, antagonistically to ethylene induced abscission.

The ROS pathway functions during leaf abscission of Capsicum, floral organ abscission of Arabidopsis, flower abscission of Lupine, and fruit abscission of longan (Dimocarpus longan) [119-122]. In the context of the longan fruit, carbohydrate stress induced fruit abscission is mediated by ROS [122]. In our study, we provide evidence that the ROS pathway functions in the AZ during oil palm ripe fruit abscission, and as a possible link between changes in the carbohydrate metabolism during fruit senescence and the abscission process in the AZ. Interestingly, a senescence-like program displaying many genes similar to those detected in oil palm fruit AZ, was observed in Arabidopsis leaves after application 5chloro-3-methyl-4-nitro-1H-pyrazole, CMNP, a compound known to be a fruit abscission stimulation agent in citrus [123].

\section{Transcript profiles of a non-shedding oil palm individual substantiate key genes and metabolic processes that function during oil palm fruit abscission.}

To validate the functions of candidates identified during ethylene treatment and natural abscission, we examined gene expression in the $\mathrm{AZ}$ of a palm that does not abscise its fruit. The AZ in this individual appears to develop normally and the non-abscission character does not appear to be due to a mutation in a gene such as in the tomato JOINTLESS or Arabidopsis BLADE-ONPETIOLE1/2 [72, 124]. Our transcript profiling results support the hypothesis that the cause of the nonshedding character in this genotype is a change in the regulation of the gene network involved in the abscission process. Furthermore, the results identify processes regulated by the abscission regulatory network during oil palm fruit abscission, given the decreased expression observed in the non-shedding palm AZ. Notably, the abundance of all the pectin related transcripts, which are characterized in having coordinated expression profiles during abscission as discussed above, are all very low in the $\mathrm{AZ}$ in the non-shedding palm, corroborating their important function for the abscission process. In addition to pectin related transcripts, many of the other transcripts we identified are either related to metabolism, or defence. One DEG was similar to thaumatin-like proteins, which are pathogenesis-related (PR) proteins with antifungal activity involved in systematically acquired resistance and stress response in plants [125, 126]. Transcripts for thaumatin-like proteins were also found highly expression in the AZ of bean and in the AZ of peach after induction by ethylene [127, 128]. 
Thaumatin-like proteins may be part of a defensive response by the plant against possible pathogen attack when the separated AZ tissue is exposed to the environment. However, it is unclear whether these proteins may also play an active role in the abscission process. While thaumatin transcripts increase in the mature fruit AZ during both ethylene and natural induced abscission and is low in the non-shedding AZ, an increase is observed in the mesocarp (Supplementary Table 6), so our evidence does not suggest a specific role for abscission, and may carry out defence functions in the AZ and adjacent tissues during and after cell separation that leads to fruit abscission.

\section{Conclusions}

The major objectives of the current study were to identify AZ specific expression related to the timing of oil palm ripe fruit abscission, in order to screen for genes that function in the $\mathrm{AZ}$, and compare to candidates identified from dicot organ abscission models. Through multiscale analyses, we identified a core set of gene candidates with highly coordinated expression in the AZ, some of which have opposite expression in the nonshedding palm fruit AZ. This is consistent with important functional roles for these genes in the AZ that lead to oil palm ripe fruit abscission. Of particular interest, we found a number of previously identified genes mainly from Arabidopsis, including PGAZ1, PGAZ2, LAC7, MAN7, HSL1, CBSX1, BEL1, with known functions related to the AZ or DZ during Arabidopsis floral organ abscission and pod dehiscence, respectively. This provides strong evidence for a widespread phylogenetic conservation between monocot and eudicot lineages in the separation zones of both fleshy and dry fruits. The identification of these genes with known abscission and dehiscence functions from model species validates this core set of genes identified with expression closely related spatially and temporally to abscission. In addition, our data points to significant metabolic changes that occur in the AZ during abscission, including key genes and transcriptional regulators related to senescence, nutrient recycling and reallocation, alternative energy supply routes and adaptive responses to oxidative stress. These results open up new perspectives in our understanding of fruit abscission in relation to metabolic changes that take place in the AZ leading up to and during abscission. In addition, the results provide potential gene markers for the selection of elite E. guineensis palms with less or delayed fruit abscission.

\section{Methods}

\section{Plant material}

For the ethylene-induced abscission transcriptome analysis, oil palm (Elaeis guineensis) fruit bunches at 30 and
150 Days After Pollination (DAP) from a tenera clone (clone $\mathrm{C}$ ) produced in Thailand were collected at the Golden Oil Palm Company Limited, Krabi province as previously reported [20]. For the E. guineensis natural abscission and gene candidate validation experiments, AZ samples at 30, 120 and 160 DAP (unripe and no abscission observed in field) and 160 DAP (ripe fruit bunches observed to shed fruit in the field) were collected. For the non-shedding individual and $\mathrm{qPCR}$ validation, AZ was sampled from two clones of backcrosses (interspecific hybrid $\times$ E. guineensis), which show contrasting fruit abscission phenotypes [25]. The first clone underwent normal fruit abscission, while the second clone retained fruit indefinitely (ripe non-shedding, RNS).

\section{AZ sampling and preparation}

For RNA extractions, the fruit bunches were collected and the base of fruits containing the AZ were sampled as follows: the spikelets were removed from the bunches, rinsed in water, then individual fruit containing the base of the fruit containing the $\mathrm{AZ}$ were removed with scalpel, then the base of the fruit containing the AZ were dissected (approximately $50 \mathrm{AZ}$ pieces were collected per sample), weighed at approximately $3 \mathrm{~g}$ then froze immediately in liquid nitrogen. Backcross material were cleaned and processed with the same procedure total AZ weights were approximately $3-6 \mathrm{~g}$.

\section{Histology and microscopy analysis}

For histology analysis, the base of the fruits containing the AZ were collected and processed as previously described and stained with the following dyes; Toluidine Blue, Ruthidium Red and DAPI for comparison [25]. Samples were then mounted on slides with Mowiol and observed with a bright-field microscope (Leica DM6000) using different objectives (X10, X20, etc. ...). To visualize the $\mathrm{AZ}$, tissue sections were also observed and photographs were taken with a Retiga 2000R camera (Qimaging).

\section{Sequencing data analysis and data mining}

AZ (30 DAP and 150 DAP) and pedicel (30 DAP) samples selected for 454 pyrosequencing were obtained by treating spikelets of fruit at $30 \mathrm{DAP}$ and $150 \mathrm{DAP}$ with ethylene at $0 \mathrm{~h}, 3 \mathrm{~h}, 6 \mathrm{~h}$ and $9 \mathrm{~h}$ as previously described [20]. Total RNA from AZ and pedicel tissue samples described above was extracted as previously [129]. The titanium kit (Roche) was used and cDNAs derived from the different tissues and different ethylene treatment time points were tagged independently and then mixed together in one sample for 454 pyrosequencing carried out by the National Center for Genetic Engineering and Biotechnology (BIOTEC), Thailand. The 454 pyrosequence analysis, de novo assembly performed following 
the methods described previously using an automated pipeline previously described and with support of the SouthGreen Bioinformatics Platform (http://southgreen.cirad.fr/), and the high performance cluster of the Unité Mixte de Recherche Amélioration Génétique et Adaptation des Plantes [130, 131]. After assembled contigs were annotated and cleaned we applied a statistical approach to analyze the transcriptome (Supplementary Fig. 2). The statistical approach was performed as previously with some modifications [131]. Statistical differences in read abundances between the AZ150 DAP (ripe fruit) untreated ethylene field samples $(0 \mathrm{~h})$ and each ethylene treatment time point $(0 \mathrm{~h}$ compared with 3 $\mathrm{h}, 6 \mathrm{~h}$ and $9 \mathrm{~h}$ ) were identified by Audic and Claverie statistics [132]. A contig was considered differentially expressed during the ethylene treatment time course when it exhibited a highly significant difference in read abundance at $P=0.01$ when compared to the untreated $0 \mathrm{~h}$ sample. The $P$ values obtained by the Audic and Claverie test were then adjusted using the Bonferroni correction to control false discovery rate (FDR). The HCA was performed to group the DEGs according to their transcription profile with the tool developed previously ([133];http://rana.lbl.gov/eisen/). DEGs were then statistically compared using Audic and Claverie statistics to the P150 DAP and AZ30 DAP samples to identify ripe fruit (AZ150 DAP) specific or enriched gene expression. Candidates were retained when there was a statistical difference between their expression in the AZ150 DAP samples compared with the P150 DAP and AZ30 DAP for at least one time point $(0 \mathrm{~h}, 3 \mathrm{~h}, 6 \mathrm{~h}$ or $9 \mathrm{~h}$; Supplementary Table 2).

\section{Illumina data analysis}

Sequencing of the three samples (AZ30, AZ120 and AZ160) collected in Thailand was complete by the company GATC Biotech (www.gatc-biotech.com). Low quality reads were removed using Cutadapt. Trimmed reads were mapped using the BWA-MEM package with default parameters [134]. Samtools was used to count mapped reads and the number of reads per kilobase and million reads (RPKM) were then calculated [135]. The oil palm predicted transcripts used for mapping was downloaded from the NCBI website (http://www.ncbi. nlm.nih.gov/, GCF_000442705.1_EG5_rna.fna; January 2015). Annotation of the DEGs with similar profiles during both ethylene and natural abscission was conducted using Mapman (https://mapman.gabipd.org/app/ mercator [136];) and expert curation based on recent literature devoted to homologous genes characterized in model plants.

\section{Primer design and $\mathrm{qPCR}$ data analysis}

Primer pairs for the statistically significant contig gene candidates were designed using Primer3 and Primer3plus. The designed primers were tested with Amplify application (http://engels.genetics.wisc.edu/amplify) to check primer pair specificity and primer dimer formation. Primers used for this study are listed on (Supplementary Table 4). Primer pairs were tested to estimate the efficiency values based on a standard curve generated from a serial dilution of pooled cDNA $(5,25,125$, 625 and 3125-fold dilutions). Only primers with efficiency values that ranged between 1.8 and 2.0 were retained for $\mathrm{qPCR}$ analysis. $\mathrm{qPCR}$ was conducted as previous described [25].

\section{Supplementary Information}

The online version contains supplementary material available at https://doi. org/10.1186/s12870-021-02874-1.

Additional file 1: Supplementary Fig. 1. Clusters AZ Overview of the
four main clusters and multiple sub-clusters found by HCA analysis. Sub-
clusters are labelled above the bars, while total number of contigs and
percentage of each cluster are indicated at the left end of bars.

Additional file 2: Supplementary Fig. 2. (454 seq data Overview of sequencing results from the ethylene treatments)

Additional file 3: Supplementary Table 1. (1957 Ethylene AZ150 DEGs annotated and expression summary)

Additional file 4: Supplementary Table 2. (502 Tissue comparison DEGs annotated and expression summary)

Additional file 5; Supplementary Table 3. (168 NA vs ET DEGS annotated and expression summary)

Additional file 6: Supplementary Table 4. ( $q P C R$ primers used in studies)

Additional file 7: Supplementary Table 5. (23 gene candidates overview of validation and expression)

Additional file 8: Supplementary Table 6. (RPKM global for entire transcriptome during Natural Abscission)

Acknowledgements

This work was supported by Franco-Thai and Thailand Graduate Institute of Science and Technology (TGIST) scholarships to KF. Financial support for the project also came from PalmElit and IRD/CIRAD to KF, FM and TJT, and from the Kasetsart University Research and Development Institute (KURDI) to CJ. We thank Anek Limsrivilai and the staff at GoldenTenera Oil Palm Plantation in Thailand, Roberto Poveda and staff at the PDA/Murrin Companies (DANEC group), Claude Louise of PalmElit in Quinindé, Ecuador for the logistical support for the study. We would also like to thank Jeremy Roberts for helpful discussions in setting up the experiments to study oil palm fruit abscission. We thank Stephanie Loubet for her technical assistance with the ethylene treated palm fruit sample collection and Gautier Sarah for the 454 reads assembly.

Timothy J. Tranbarger's information:

ORCID ID: 0000-0001-6278-8321.

ResearcherlD: B-3123-2011.

Frontiers (http://loop.frontiersin.org/people/108686/overview). ResearchGate (https://www.researchgate.net/profile/Timothy_Tranbarger). Publons (https://publons.com/researcher/927118/timothy-john-tranbarger/). DIADE (http://diade.ird.fr/en/teams/f2fteam.html).

Authors' contributions

TJT planned and supervised all aspects of the study. PA, CJ and TJT coordinated the logistics for fieldwork experiments. TJT, FM, PR and CJ, performed the ethylene experiments and collected samples for RNA isolation 
and histological studies. ST performed the 454 sequencing. KF and JS extracted total RNA, designed gene specific primers, characterized the nonshedding fruit individual, carried out the gene candidate validation strategy, and performed GPCR analysis. FM performed the Illumina data analysis. SD performed the statistical analysis of the transcriptome data. SD, TJ, FM and TJT performed the manual annotation. JLV, KF and MC prepared samples for histological analysis and performed microscopic analyses. TJ wrote the metabolic section. KF and TJT wrote the article with contributions from all authors. The author (s) read and approved the final manuscript.

\section{Funding}

This work was supported by Franco-Thai and Thailand Graduate Institute of Science and Technology (TGIST) scholarships to KF. Financial and scholarship support for the project also came from PalmElit, IRD (Allocations de recherche pour une thèse au Sud, ARTS) and CIRAD to KF, FM and TJT, and from the Kasetsart University Research and Development Institute (KURDI) to CJ.

\section{Availability of data and materials}

The data discussed in this publication have been deposited in NCBI's Gene Expression Omnibus and are accessible through GEO Series accession number GSE166314 https://www.ncbi.nlm.nih.gov/geo/query/acc.cgi?acc= GSE166314.

\section{Ethics approval and consent to participate}

Not applicable.

\section{Consent for publication}

I am the author responsible for the submission of this article and I accept the conditions of submission and the BMC Copyright and License Agreement as detailed within the online submission form.

- No studies involving human participants, human data or human tissue: "Not applicable".

- The manuscript does not contain any individual person's data in any form (including any individual details, images or videos): "Not applicable".

\section{Competing interests}

No competing interests.

\section{Author details}

'UMR DIADE, Institut de Recherche Pour le Développement, Université de Montpellier, IRD Centre de Montpellier, 911 Avenue Agropolis BP 64501, 34394 Cedex 5 Montpellier, France. ${ }^{2}$ Grow A Green Co, Ltd. 556 Maha Chakraphat Rd. Namaung, Chachoengsao, Chachoengsao Province 24000, Thailand. ${ }^{3}$ CIRAD, DIADE, F-34398 Montpellier, France. ${ }^{4}$ PalmElit SAS, Montferrier-sur-Lez, France. ${ }^{5}$ National Science and Technology Development Agency, 111 Thailand Science Park, Phahonyothin Road, Pathum Thani, Thailand. 'Department of Genetics, Faculty of Science, Kasetsart University Bangkhen Campus, 50 Phahonyothin Road Jatujak, Bangkok, Thailand. ${ }^{7}$ CIRA D, UMR AGAP, F-34398 Montpellier, France. ${ }^{8}$ AGAP, Univ Montpellier, CIRAD, INRAE, Institut Agro, Montpellier, France.

Received: 11 December 2020 Accepted: 1 February 2021

Published online: 11 February 2021

\section{References}

1. Butler L. Inherited characters in the tomato. II Jointless pedicel. J Hered. 1936;27(1):25-6

2. Tranbarger TJ, Tadeo FR. Diversity and functional dynamics of fleshy fruit abscission zones. Ann Plant Rev Online. 2020;3:1-64.

3. Addicott FT. Abscission. Berkeley and Los Angeles, California: University of California Press; 1982.

4. Estornell LH, Agusti J, Merelo P, Talon M, Tadeo FR. Elucidating mechanisms underlying organ abscission. Plant Sci. 2013;199-200:48-60.

5. Lee Y, Yoon TH, Lee J, Jeon SY, Lee JH, Lee MK, Chen H, Yun J, Oh SY, Wen $X$, et al. A lignin molecular brace controls precision processing of cell walls critical for surface integrity in Arabidopsis. Cell. 2018;173:1-13.

6. Meir S, Philosoph-Hadas S, Riov J, Tucker ML, Patterson SE, Roberts JA. Reevaluation of the ethylene-dependent and -independent pathways in the regulation of floral and organ abscission. J Exp Bot. 2019;70(5):1461-7.
7. Patharkar OR, Walker JC. Advances in abscission signaling. J Exp Bot. 2018; 69(4):733-40.

8. Sawicki M, Ait Barka E, Clement C, Vaillant-Gaveau N, Jacquard C. Cross-talk between environmental stresses and plant metabolism during reproductive organ abscission. J Exp Bot. 2015;66(7):1707-19.

9. Tisné S, Denis M, Domonhédo H, Pallas B, Cazemajor M, Tranbarger TJ, Morcillo F. Environmental and trophic determinism of fruit abscission and outlook with climate change in tropical regions. Plant Environ Interact. 2020;1(1):17-28

10. Patterson SE. Cutting loose. Abscission and dehiscence in Arabidopsis. Plant Physiol. 2001;126(2):494-500

11. Meir S, Hunter DA, Chen JC, Halaly V, Reid MS. Molecular changes occurring during acquisition of abscission competence following auxin depletion in Mirabilis jalapa. Plant Physiol. 2006;141(4):1604-16.

12. Meir S, Philosoph-Hadas S, Sundaresan S, Selvaraj KS, Burd S, Ophir R, Kochanek B, Reid MS, Jiang CZ, Lers A. Microarray analysis of the abscissionrelated transcriptome in the tomato flower abscission zone in response to auxin depletion. Plant Physiol. 2010;154(4):1929-56.

13. Meir S, Sundaresan S, Riov J, Agarwal I, Philosoph-Hadas S. Role of auxin depletion in abscission control. Stewart Postharvest Rev. 2015;2(2):1-15.

14. Tucker ML, Kim J. Abscission research: what we know and what we still need to study. Stewart Postharvest Rev. 2015;2(1):1-7.

15. Burr CA, Leslie ME, Orlowski SK, Chen I, Wright CE, Daniels MJ, Liljegren SJ. CAST AWAY, a membrane-associated receptor-like kinase, inhibits organ abscission in Arabidopsis. Plant Physiol. 2011;156(4):1837-50.

16. Liljegren SJ, Leslie ME, Darnielle L, Lewis MW, Taylor SM, Luo R, Geldner N, Chory J, Randazzo PA, Yanofsky MF, et al. Regulation of membrane trafficking and organ separation by the NEVERSHED ARF-GAP protein. Development. 2009;136(11):1909-18.

17. Henderson J, Osborne DJ. Cell separation and anatomy of abscission in the oil palm, Elaeis guineensis Jacq. J Exp Bot. 1990;41(2):203-10.

18. Osborne DJ, Henderson J, Corley RHV. Controlling fruit shedding in the oil palm. Endeavour. 1992;16(4):173-7.

19. Henderson J, Osborne DJ. Intertissue signaling during the 2-phase abscission in oil palm fruit. J Exp Bot. 1994;45(276):943-51.

20. Roongsattham P, Morcillo F, Jantasuriyarat C, Pizot M, Moussu S, Jayaweera D, Collin M, Gonzalez-Carranza ZH, Amblard P, Tregear JW, et al. Temporal and spatial expression of polygalacturonase gene family members reveals divergent regulation during fleshy fruit ripening and abscission in the monocot species oil palm. BMC Plant Biol. 2012;12.

21. Henderson J, Davies HA, Heyes SJ, Osborne DJ. The study of a monocotyledon abscission zone using microscopic, chemical, enzymatic and solid state C-13 CP/MAS NMR analyses. Phytochemistry. 2001;56(2):131-9.

22. Roberts JA, Elliott KA, Gonzalez-Carranza ZH. Abscission, dehiscence, and other cell separation processes. Annu Rev Plant Biol. 2002;53(1):131-58.

23. Roongsattham $P$, Morcillo $F$, Fooyontphanich $K$, Jantasuriyarat $C$, Tragoonrung S, Amblard P, Collin M, Mouille G, Verdeil JL, Tranbarger TJ. Cellular and pectin dynamics during abscission zone development and ripe fruit abscission of the monocot oil palm. Front Plant Sci. 2016;7:540.

24. Tranbarger TJ, Fooyontphanich K, Roongsattham P, Pizot M, Collin M, Jantasuriyarat C, Suraninpong P, Tragoonrung S, Dussert S, Verdeil JL, et al. Transcriptome analysis of Cell Wall and NAC domain transcription factor genes during Elaeis guineensis fruit ripening: evidence for widespread conservation within monocot and Eudicot lineages. Front Plant Sci. 2017;8:603.

25. Fooyontphanich K, Morcillo F, Amblard P, Collin M, Jantasuriyarat C, Tangphatsornruang S, Verdeil JL, Tranbarger TJ. A phenotypic test for delay of abscission and non-abscission oil palm fruit and validation by abscission marker gene expression analysis. Acta Hortic. 2016;1119:97-104.

26. Jung KW, Kim YY, Yoo KS, Ok SH, Cui MH, Jeong BC, Yoo SD, Jeung JU, Shin JS. A cystathionine-beta-synthase domain-containing protein, CBSX2, regulates endothecial secondary cell wall thickening in anther development. Plant Cell Physiol. 2013;54(2):195-208.

27. Yoo KS, OK SH, Jeong BC, Jung KW, Cui MH, Hyoung S, Lee MR, Song HK, Shin JS. Single cystathionine beta-synthase domain-containing proteins modulate development by regulating the thioredoxin system in Arabidopsis. Plant Cell. 2011;23(10):3577-94.

28. Missihoun TD, Kotchoni SO, Bartels D, Bonham-Smith P. Active sites of reduced epidermal Fluorescence1 (REF1) isoforms contain amino acid substitutions that are different between monocots and dicots. PLoS One. 2016;11(10):e0165867. 
29. Gonzalez-Carranza ZH, Whitelaw CA, Swarup R, Roberts JA. Temporal and spatial expression of a polygalacturonase during leaf and flower abscission in oilseed rape and Arabidopsis. Plant Physiol. 2002;128(2):534-43.

30. Ogawa M, Kay P, Wilson S, Swain SM. Arabidopsis dehiscence zone polygalacturonase1 (ADPG1), ADPG2, and QUARTET2 are Polygalacturonases required for cell separation during reproductive development in Arabidopsis. Plant Cell. 2009;21(1):216-33.

31. He $\mathrm{H}$, Bai M, Tong $\mathrm{P}, \mathrm{Hu}$ Y, Yang M, Wu H. CELLULASE6 and MANNANASEY affect cell differentiation and Silique dehiscence. Plant Physiol. 2018;176(3): 2186-201.

32. Jinn TL, Stone JM, Walker JC. HAESA, an Arabidopsis leucine-rich repeat receptor kinase, controls floral organ abscission. Genes Dev. 2000;14(1):108-17.

33. Yoon J, Cho LH, Kim SL, Choi H, Koh HJ, An G. The BEL 1-type homeobox gene SH5 induces seed shattering by enhancing abscission-zone development and inhibiting lignin biosynthesis. Plant J. 2014;79(5):717-28.

34. Shin K, Lee S, Song WY, Lee RA, Lee I, Ha K, Koo JC, Park SK, Nam HG, Lee Y, et al. Genetic identification of ACC-RESISTANT2 reveals involvement of LYSI NE HISTIDINE TRANSPORTER1 in the uptake of 1-aminocyclopropane-1carboxylic acid in Arabidopsis thaliana. Plant Cell Physiol. 2015;56(3):572-82.

35. Rauf M, Arif M, Fisahn J, Xue GP, Balazadeh S, Mueller-Roeber B. NAC transcription factor speedy hyponastic growth regulates flooding-induced leaf movement in Arabidopsis. Plant Cell. 2013;25(12):4941-55.

36. Song S, Huang H, Gao H, Wang J, Wu D, Liu X, Yang S, Zhai Q, Li C, Qi T, et al. Interaction between MYC2 and ETHYLENE INSENSITIVE3 modulates antagonism between jasmonate and ethylene signaling in Arabidopsis. Plant Cell. 2014;26(1):263-79.

37. Nalam VJ, Alam S, Keereetaweep J, Venables B, Burdan D, Lee H, Trick HN, Sarowar S, Makandar R, Shah J. Facilitation of Fusarium graminearum infection by 9-Lipoxygenases in Arabidopsis and wheat. Mol Plant-Microbe Interact. 2015;28(10):1142-52

38. Yuan HM, Liu WC, LU YT. CATALASE2 coordinates SA-mediated repression of both Auxin accumulation and JA biosynthesis in plant defenses. Cell Host Microbe. 2017;21(2):143-55

39. Barbez E, Kubes M, Rolcik J, Beziat C, Pencik A, Wang B, Rosquete MR, Zhu J, Dobrev $\mathrm{PI}$, Lee $\mathrm{Y}$, et al. A novel putative auxin carrier family regulates intracellular auxin homeostasis in plants. Nature. 2012:485(7396):119-22.

40. Jaillais Y, Fobis-Loisy I, Miege C, Rollin C, Gaude T. AtSNX1 defines an endosome for auxin-carrier trafficking in Arabidopsis. Nature. 2006; 443(7107):106-9

41. Wang C, Yan X, Chen Q, Jiang N, Fu W, Ma B, Liu J, Li C, Bednarek SY, Pan J. Clathrin light chains regulate clathrin-mediated trafficking, auxin signaling, and development in Arabidopsis. Plant Cell. 2013;25(2):499-516.

42. Westfall CS, Sherp AM, Zubieta C, Alvarez S, Schraft E, Marcellin R, Ramirez L, Jez JM. Arabidopsis thaliana GH3.5 acyl acid amido synthetase mediates metabolic crosstalk in auxin and salicylic acid homeostasis. Proc Natl Acad Sci U S A. 2016;113(48):13917-22.

43. Liscum E, Reed JW. Genetics of aux/IAA and ARF action in plant growth and development. Plant Mol Biol. 2002;49(3-4):387-400.

44. Jurado S, Abraham Z, Manzano C, Lopez-Torrejon G, Pacios LF, Del Pozo JC. The Arabidopsis cell cycle F-box protein SKP2A binds to auxin. Plant Cell. 2010;22(12):3891-904.

45. Kim CY, Bove J, Assmann SM. Overexpression of wound-responsive RNAbinding proteins induces leaf senescence and hypersensitive-like cell death. New Phytol. 2008;180(1):57-70.

46. Thomas H, Ougham H. The stay-green trait. J Exp Bot. 2014;65(14):3889-900.

47. Tran LS, Nakashima K, Sakuma Y, Osakabe Y, Qin F, Simpson SD, Maruyama K, Fujita Y, Shinozaki K, Yamaguchi-Shinozaki K. Co-expression of the stressinducible zinc finger homeodomain ZFHD1 and NAC transcription factors enhances expression of the ERD1 gene in Arabidopsis. Plant J. 2007:49(1): 46-63.

48. Doyle EA, Lane AM, Sides JM, Mudgett MB, Monroe JD. An alpha-amylase (At4g25000) in Arabidopsis leaves is secreted and induced by biotic and abiotic stress. Plant Cell Environ. 2007;30(4):388-98.

49. Garapati P, Xue GP, Munne-Bosch S, Balazadeh S. Transcription factor ATAF1 in Arabidopsis promotes senescence by direct regulation of key chloroplast maintenance and senescence transcriptional cascades. Plant Physiol. 2015; 168(3):1122-39.

50. Iwase A, Mitsuda N, Koyama T, Hiratsu K, Kojima M, Arai T, Inoue Y, Seki M, Sakakibara H, Sugimoto K, et al. The AP2/ERF transcription factor WIND1 controls cell dedifferentiation in Arabidopsis. Curr Biol. 2011;21(6):508-14.
51. Zhu X, Chen J, Xie Z, Gao J, Ren G, Gao S, Zhou X, Kuai B. Jasmonic acid promotes degreening via MYC2/3/4- and ANAC019/055/072-mediated regulation of major chlorophyll catabolic genes. Plant J. 2015;84(3):597-610.

52. Herbers K, Monke G, Badur R, Sonnewald U. A simplified procedure for the subtractive CDNA cloning of photoassimilate-responding genes: isolation of CDNAs encoding a new class of pathogenesis-related proteins. Plant Mol Biol. 1995;29(5):1027-38.

53. Léran S, Varala K, Boyer JC, Chiurazzi M, Crawford N, Daniel-Vedele F, David L, Dickstein R, Fernandez E, Forde B, et al. A unified nomenclature of NITR ATE TRANSPORTER 1/PEPTIDE TRANSPORTER family members in plants. Trends Plant Sci. 2014;19(1):5-9.

54. Tannert M, May A, Ditfe D, Berger S, Balcke GU, Tissier A, Kock M. Pi starvation-dependent regulation of ethanolamine metabolism by phosphoethanolamine phosphatase PECP1 in Arabidopsis roots. J Exp Bot. 2018;69(3):467-81.

55. Zrenner R, Riegler $H$, Marquard CR, Lange PR, Geserick C, Bartosz CE, Chen $\mathrm{CT}$, Slocum RD. A functional analysis of the pyrimidine catabolic pathway in Arabidopsis. New Phytol. 2009;183(1):117-32.

56. Dietrich K, Weltmeier F, Ehlert A, Weiste C, Stahl M, Harter K, Droge-Laser W. Heterodimers of the Arabidopsis transcription factors bZIP1 and bZIP53 reprogram amino acid metabolism during low energy stress. Plant Cell. 2011;23(1):381-95.

57. Yuan W, Zhang D, Song T, Xu F, Lin S, Xu W, Li Q, Zhu Y, Liang J, Zhang J. Arabidopsis plasma membrane H+-ATPase genes AHA2 and AHA7 have distinct and overlapping roles in the modulation of root tip $\mathrm{H}+$ efflux in response to low-phosphorus stress. J Exp Bot. 2017;68(7):1731-41.

58. Rojas CM, Senthil-Kumar M, Wang K, Ryu CM, Kaundal A, Mysore KS. Glycolate oxidase modulates reactive oxygen species-mediated signal transduction during nonhost resistance in Nicotiana benthamiana and Arabidopsis. Plant Cell. 2012;24(1):336-52.

59. Dubreuil-Maurizi C, Vitecek J, Marty L, Branciard L, Frettinger P, Wendehenne D, Meyer AJ, Mauch F, Poinssot B. Glutathione deficiency of the Arabidopsis mutant pad2-1 affects oxidative stress-related events, defense gene expression, and the hypersensitive response. Plant Physiol. 2011;157(4):2000-12.

60. Stiti N, Missihoun TD, Kotchoni SO, Kirch HH, Bartels D. Aldehyde dehydrogenases in Arabidopsis thaliana: biochemical requirements, metabolic pathways, and functional analysis. Front Plant Sci. 2011;2:65.

61. Chen KM, Holmstrom M, Raksajit W, Suorsa M, Piippo M, Aro EM. Small chloroplast-targeted DnaJ proteins are involved in optimization of photosynthetic reactions in Arabidopsis thaliana. BMC Plant Biol. 2010;10:43.

62. Sugliani M, Abdelkefi H, Ke H, Bouveret E, Robaglia C, Caffarri S, Field B. An ancient bacterial signaling pathway regulates chloroplast function to influence growth and development in Arabidopsis. Plant Cell. 2016;28(3): $661-79$.

63. Selinski J, Scheibe R, Day DA, Whelan J. Alternative oxidase is positive for plant performance. Trends Plant Sci. 2018;23(7):588-97.

64. Wojtera-Kwiczor J, Gross F, Leffers HM, Kang M, Schneider M, Scheibe R. Transfer of a redox-signal through the cytosol by redox-dependent Microcompartmentation of glycolytic enzymes at mitochondria and actin cytoskeleton. Front Plant Sci. 2013;3:284.

65. Dong Y, Wang YZ. Seed shattering: from models to crops. Front Plant Sci. 2015;6.

66. Ferrandiz C. Regulation of fruit dehiscence in Arabidopsis. J Exp Bot. 2002; 53(377):2031-8

67. Patharkar OR, Walker JC. Connections between abscission, dehiscence, pathogen defense, drought tolerance, and senescence. Plant Sci. 2019;284: 25-9.

68. Arnaud N, Lawrenson T, Ostergaard L, Sablowski R. The same regulatory point mutation changed seed-dispersal structures in evolution and domestication. Curr Biol. 2011;21(14):1215-9.

69. Ballester P, Ferrandiz C. Shattering fruits: variations on a dehiscent theme. Curr Opin Plant Biol. 2017;35:68-75.

70. Lin ZW, Li XR, Shannon LM, Yeh CT, Wang ML, Bai GH, Peng Z, Li JR, Trick $H N$, Clemente TE, et al. Parallel domestication of the Shattering1 genes in cereals. Nat Genet. 2012;44(6):720-U154.

71. Konishi S, Izawa T, Lin SY, Ebana K, Fukuta Y, Sasaki T, Yano M. An SNP caused loss of seed shattering during rice domestication. Science. 2006: 312(5778):1392-6. 
72. McKim SM, Stenvik GE, Butenko MA, Kristiansen W, Cho SK, Hepworth SR, Aalen RB, Haughn GW. The BLADE-ON-PETIOLE genes are essential for abscission zone formation in Arabidopsis. Development. 2008;135(8):1537-46.

73. Li YL, Yu YK, Zhu KM, Ding LN, Wang Z, Yang YH, Cao J, Xu LZ, Li YM, Tan $\mathrm{XL}$. Down-regulation of MANNANASE7 gene in Brassica napus L. enhances silique dehiscence-resistance. Plant Cell Rep. 2021:40(2):361-74.

74. Arsovski AA, Popma TM, Haughn GW, Carpita NC, McCann MC, Western TL. AtBXL1 encodes a bifunctional beta-D-xylosidase/alpha-Larabinofuranosidase required for pectic arabinan modification in Arabidopsis mucilage secretory cells. Plant Physiol. 2009;150(3):1219-34.

75. Draeger C, Ndinyanka Fabrice T, Gineau E, Mouille G, Kuhn BM, Moller I, Abdou MT, Frey B, Pauly M, Bacic A, et al. Arabidopsis leucine-rich repeat extensin (LRX) proteins modify cell wall composition and influence plant growth. BMC Plant Biol. 2015;15:155.

76. Enns LC, Kanaoka MM, Torii KU, Comai L, Okada K, Cleland RE. Two callose synthases, GSL1 and GSL5, play an essential and redundant role in plant and pollen development and in fertility. Plant Mol Biol. 2005;58(3):333-49.

77. Van de Wouwer D, Vanholme R, Decou R, Goeminne G, Audenaert D, Nguyen L, Hofer R, Pesquet E, Vanholme B, Boerjan W. Chemical genetics uncovers novel inhibitors of lignification, including p-lodobenzoic acid targeting CINNAMATE-4-HYDROXYLASE. Plant Physiol. 2016;172(1):198-220.

78. Fuglsang AT, Kristensen A, Cuin TA, Schulze WX, Persson J, Thuesen KH, Ytting CK, Oehlenschlaeger CB, Mahmood K, Sondergaard TE, et al. Receptor kinase-mediated control of primary active proton pumping at the plasma membrane. Plant J. 2014;80(6):951-64.

79. Santi S, Schmidt W. Dissecting iron deficiency-induced proton extrusion in Arabidopsis roots. New Phytol. 2009;183(4):1072-84.

80. Agusti J, Gimeno J, Merelo P, Serrano R, Cercos M, Conesa A, Talon M, Tadeo FR. Early gene expression events in the laminar abscission zone of abscission-promoted citrus leaves after a cycle of water stress/rehydration: involvement of CitbHLH1. J Exp Bot. 2012;63(17):6079-91.

81. Briegas B, Corbacho J, Parra-Lobato MC, Paredes MA, Labrador J, Gallardo M, Gomez-Jimenez MC. Transcriptome and hormone analyses revealed insights into hormonal and vesicle trafficking regulation among Olea europaea fruit tissues in late development. Int J Mol Sci. Int J Mol Sci. 2020;21(14):4819.

82. Corbacho J, Romojaro F, Pech JC, Latche A, Gomez-Jimenez MC. Transcriptomic events involved in melon mature-fruit abscission comprise the sequential induction of cell-wall degrading genes coupled to a stimulation of endo and exocytosis. PLoS One. 2013;8(3):e58363.

83. Gil-Amado JA, Gomez-Jimenez MC. Transcriptome analysis of mature fruit abscission control in olive. Plant Cell Physiol. 2013;54(2):244-69.

84. Sundaresan S, Philosoph-Hadas S, Riov J, Salim S, Meir S. Expression kinetics of regulatory genes involved in the vesicle trafficking processes operating in tomato flower abscission zone cells during pedicel abscission. Life (Basel). 2020;10(11):273.

85. Sundaresan S, Philosoph-Hadas S, Riov J, Belausov E, Kochanek B, Tucker ML, Meir S. Abscission of flowers and floral organs is closely associated with alkalization of the cytosol in abscission zone cells. J Exp Bot. 2015;66(5): 1355-68.

86. Merelo P, Agusti J, Arbona V, Costa ML, Estornell LH, Gomez-Cadenas A, Coimbra S, Gomez MD, Perez-Amador MA, Domingo C, et al. Cell Wall remodeling in abscission zone cells during ethylene-promoted fruit abscission in Citrus. Front Plant Sci. 2017;8:126.

87. Bonghi C, Rascio N, Ramina A, Casadoro G. Cellulase and Polygalacturonase involvement in the abscission of leaf and fruit explants of peach. Plant Mol Biol. 1992;20(5):839-48.

88. Burns JK, Lewandowski DJ, Nairn CJ, Brown GE. Endo-1,4-beta-glucanase gene expression and cell wall hydrolase activities during abscission in Valencia orange. Physiol Plant. 1998;102(2):217-25.

89. Kalaitzis P, Koehler SM, Tucker ML. Cloning of a tomato Polygalacturonase expressed in abscission. Plant Mol Biol. 1995;28(4):647-56

90. Kalaitzis P, Solomos T, Tucker ML. Three different polygalacturonases are expressed in tomato leaf and flower abscission, each with a different temporal expression pattern. Plant Physiol. 1997;113(4):1303-8.

91. Taylor JE, Tucker GA, Lasslett Y, Smith CJS, Arnold CM, Watson CF, Schuch W, Grierson D, Roberts JA. Polygalacturonase expression during leaf abscission of Normal and transgenic tomato plants. Planta. 1991;183(1):133-8.

92. Taylor JE, Webb STJ, Coupe SA, Tucker GA, Roberts JA. Changes in Polygalacturonase activity and solubility of Poluronides during ethylenestimulated leaf abscission in Sambucus-Nigra. J Exp Bot. 1993:44(258):93-8.
93. Grierson D, Tucker GA, Keen J, Ray J, Bird CR, Schuch W. Sequencing and identification of a cDNA clone for tomato polygalacturonase. Nucleic Acids Res. 1986;14(21):8595-603.

94. Sheehy RE, Kramer M, Hiatt WR. Reduction of polygalacturonase activity in tomato fruit by antisense RNA. Proc Natl Acad Sci U S A. 1988;85(23):8805-9.

95. Smith CJS, Watson CF, Ray J, Bird CR, Morris PC, Schuch W, Grierson D. Antisense Rna inhibition of Polygalacturonase gene-expression in transgenic tomatoes. Nature. 1988;334(6184):724-6.

96. Hong SB, Tucker ML. Genomic organization of six tomato polygalacturonases and 5 ' upstream sequence identity with tap1 and win2 genes. Mol Gen Genet. 1998;258(5):479-87.

97. Mohnen D. Pectin structure and biosynthesis. Curr Opin Plant Biol. 2008; 11(3):266-77.

98. Wolf S, Greiner S. Growth control by cell wall pectins. Protoplasma. 2012; 249:169-75.

99. Verlent I, Smout C, Duvetter T, Hendrickx ME, Van Loey A. Effect of temperature and pressure on the activity of purified tomato polygalacturonase in the presence of pectins with different patterns of methyl esterification. Innov Food Sci Emerg. 2005;6(3):293-303.

100. Bleecker AB, Patterson SE. Last exit: senescence, abscission, and meristem arrest in Arabidopsis. Plant Cell. 1997;9(7):1169-79.

101. Lanahan MB, Yen HC, Giovannoni JJ, Klee HJ. The never ripe mutation blocks ethylene perception in tomato. Plant Cell. 1994;6(4):521-30.

102. Butenko MA, Patterson SE, Grini PE, Stenvik GE, Amundsen SS, Mandal A, Aalen RB. Inflorescence deficient in abscission controls floral organ abscission in Arabidopsis and identifies a novel family of putative ligands in plants. Plant Cell. 2003;15(10):2296-307.

103. Stenvik GE, Tandstad NM, Guo Y, Shi CL, Kristiansen W, Holmgren A, Clark SE, Aalen RB, Butenko MA. The EPIP peptide of INFLORESCENCE DEFICIENT IN ABSCISSION is sufficient to induce abscission in arabidopsis through the receptor-like kinases HAESA and HAESA-LIKE2. Plant Cell. 2008;20(7):1805-17.

104. Stø IM, Orr RJS, Fooyontphanich K, Jin X, Knutsen JMB, Fischer U, Tranbarger TJ, Nordal I, Aalen RB. Conservation of the abscission signaling peptide IDA during angiosperm evolution: withstanding genome duplications and gain and loss of the receptors HAE/HSL2. Front Plant Sci. 2015;6.

105. Tranbarger TJ, Domonhedo H, Cazemajor M, Dubreuil C, Fischer U, Morcillo F. The PIP peptide of INFLORESCENCE DEFICIENT IN ABSCISSION enhances populus leaf and Elaeis quineensis fruit abscission. Plants. 2019;8(6):143.

106. Chen MK, Lee PF, Yang CH. Delay of FLOWER senescence and abscission in Arabidopsis transformed with an FOREVER YOUNG FLOWER homolog from Oncidium orchid. Plant Signal Behav. 2011;6(11):1841-3.

107. Lim PO, Kim HJ, Nam HG. Leaf senescence. Annu Rev Plant Biol. 2007;58: 115-36.

108. Gaufichon L, Marmagne A, Belcram K, Yoneyama T, Sakakibara Y, Hase T, Grandjean O, Clement G, Citerne S, Boutet-Mercey S, et al. ASN1-encoded asparagine synthetase in floral organs contributes to nitrogen filling in Arabidopsis seeds. Plant J. 2017;91(3):371-93.

109. Angkawijaya AE, Nakamura Y. Arabidopsis PECP1 and PS2 are phosphate starvation-inducible phosphocholine phosphatases. Biochem Biophys Res Commun. 2017;494(1-2):397-401.

110. Ayadi A, David P, Arrighi JF, Chiarenza S, Thibaud MC, Nussaume L, Marin E. Reducing the genetic redundancy of Arabidopsis PHOSPHATE TRAN SPORTER1 transporters to study phosphate uptake and signaling. Plant Physiol. 2015;167(4):1511-26.

111. Liu TY, Huang TK, Yang SY, Hong YT, Huang SM, Wang FN, Chiang SF, Tsai SY, Lu WC, Chiou TJ. Identification of plant vacuolar transporters mediating phosphate storage. Nat Commun. 2016;7:11095.

112. Pedrotti L, Weiste C, Nägele T, Wolf E, Lorenzin F, Dietrich K, Mair A, Weckwerth W, Teige M, Baena-González E, et al. Snf1-RELATED KINASE1controlled $C / S_{1}$-bZIP signaling activates alternative mitochondrial metabolic pathways to ensure plant survival in extended darkness. Plant Cell. 2018; 30(2):495.

113. Hildebrandt TM, Nunes Nesi A, Araujo WL, Braun HP. Amino acid catabolism in plants. Mol Plant. 2015;8(11):1563-79.

114. Diab H, Limami AM. Reconfiguration of $\mathrm{N}$ metabolism upon hypoxia stress and recovery: roles of Alanine Aminotransferase (AlaAT) and Glutamate Dehydrogenase (GDH). Plants. 2016;5(2):25.

115. Kim JM, To TK, Matsui A, Tanoi K, Kobayashi NI, Matsuda F, Habu Y, Ogawa $D$, Sakamoto T, Matsunaga S, et al. Acetate-mediated novel survival strategy against drought in plants. Nat Plants. 2017;3:17097. 
116. Baud S, Lepiniec L. Physiological and developmental regulation of seed oil production. Prog Lipid Res. 2010;49(3):235-49.

117. Hinz M, Wilson IW, Yang J, Buerstenbinder K, Llewellyn D, Dennis ES, Sauter M, Dolferus R. Arabidopsis RAP2.2: an ethylene response transcription factor that is important for hypoxia survival. Plant Physiol. 2010;153(2):757-72.

118. Liang Y, Jiang C, Liu Y, Gao Y, Lu J, Aiwaili P, Fei Z, Jiang CZ, Hong B, Ma C, et al. Auxin regulates sucrose transport to repress petal abscission in rose (Rosa hybrida). Plant Cell. 2020.

119. Kucko A, Wilmowicz E, Pokora W, Alche JD. Disruption of the auxin gradient in the abscission zone area evokes asymmetrical changes leading to flower separation in yellow lupine. Int J Mol Sci. 2020;21(11):3815.

120. Sakamoto M, Munemura I, Tomita R, Kobayashi K. Involvement of hydrogen peroxide in leaf abscission signaling, revealed by analysis with an in vitro abscission system in Capsicum plants. Plant J. 2008;56(1):13-27.

121. Xu P, Chen H, Cai W. Transcription factor CDF4 promotes leaf senescence and floral organ abscission by regulating abscisic acid and reactive oxygen species pathways in Arabidopsis. EMBO Rep. 2020;21(7):e48967.

122. Yang ZQ, Zhong XM, Fan Y, Wang HC, Li JG, Huang XM. Burst of reactive oxygen species in pedicel-mediated fruit abscission after carbohydrate supply was cut off in longan (Dimocarpus longan). Front Plant Sci. 2015;6.

123. Alferez F, Zhong GY, Burns JK. A citrus abscission agent induces anoxia- and senescence-related gene expression in Arabidopsis. J Exp Biol. 2007:58(10): 2451-62.

124. Mao L, Begum D, Chuang HW, Budiman MA, Szymkowiak EJ, Irish EE, Wing RA. JOINTLESS is a MADS-box gene controlling tomato flower abscission zone development. Nature. 2000;406(6798):910-3.

125. Hejgaard J, Jacobsen S, Svendsen I. Two antifungal thaumatin-like proteins from barley grain. FEBS Lett. 1991;291(1):127-31.

126. Vigers AJ, Roberts WK, Selitrennikoff CP. A new family of plant antifungal proteins. Mol Plant-Microbe Interact. 1991;4(4):315-23.

127. Del Campillo $E$, Lewis $L N$. Identification and kinetics of accumulation of proteins induced by ethylene in bean abscission zones. Plant Physiol. 1992; 98(3):955-61.

128. Ruperti B, Cattivelli L, Pagni S, Ramina A. Ethylene-responsive genes are differentially regulated during abscission, organ senescence and wounding in peach (Prunus persica). J Exp Bot. 2002;53(368):429-37.

129. Morcillo F, Gagneur C, Adam H, Richaud F, Singh R, Cheah SC, Rival A, Duval Y, Tregear JW. Somaclonal variation in micropropagated oil palm. Characterization of two novel genes with enhanced expression in epigenetically abnormal cell lines and in response to auxin. Tree Physiol. 2006;26(5):585-94.

130. Argout X, Fouet O, Wincker P, Gramacho K, Legavre T, Sabau X, Risterucci AM, Da Silva C, Cascardo J, Allegre M, et al. Towards the understanding of the cocoa transcriptome: Production and analysis of an exhaustive dataset of ESTs of Theobroma cacao $L$ generated from various tissues and under various conditions. BMC Genomics. 2008:9:512.

131. Tranbarger TJ, Dussert S, Joet T, Argout X, Summo M, Champion A, Cros D Omore A, Nouy B, Morcillo F. Regulatory mechanisms underlying oil palm fruit mesocarp maturation, ripening, and functional specialization in lipid and carotenoid metabolism. Plant Physiol. 2011;156(2):564-84.

132. Audic S, Claverie JM. The significance of digital gene expression profiles. Genome Res. 1997;7(10):986-95.

133. Eisen JA. Phylogenomics: improving functional predictions for uncharacterized genes by evolutionary analysis. Genome Res. 1998;8(3):163-7.

134. Li H. Aligning sequence reads, clone sequences and assembly contigs with BWA-MEM. arXiv. 2013. p. 1303.3997. https://arxiv.org/abs/1303.3997.

135. Li H, Handsaker B, Wysoker A, Fennell T, Ruan J, Homer N, Marth G, Abecasis $\mathrm{G}$, Durbin R. Genome project data processing S. the sequence alignment/ map format and SAMtools. Bioinformatics. 2009;25(16):2078-9.

136. Lohse M, Nagel A, Herter T, May P, Schroda M, Zrenner R, Tohge T, Fernie AR, Stitt M, Usadel B. Mercator: a fast and simple web server for genome scale functional annotation of plant sequence data. Plant Cell Environ. 2014; 37(5):1250-8.

\section{Publisher's Note}

Springer Nature remains neutral with regard to jurisdictional claims in published maps and institutional affiliations.

\section{Ready to submit your research? Choose BMC and benefit from}

- fast, convenient online submission

- thorough peer review by experienced researchers in your field

- rapid publication on acceptance

- support for research data, including large and complex data types

- gold Open Access which fosters wider collaboration and increased citations

- maximum visibility for your research: over $100 \mathrm{M}$ website views per year

At BMC, research is always in progress.

Learn more biomedcentral.com/submissions 